\title{
Enhanced solar energy absorption by internally-mixed black carbon in snow grains
}

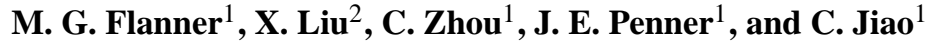 \\ ${ }^{1}$ Department of Atmospheric, Oceanic and Space Sciences, University of Michigan, Ann Arbor MI, USA \\ ${ }^{2}$ Atmospheric Science and Global Change Division, Pacific Northwest National Laboratory, Richland WA, USA
}

Correspondence to: M. G. Flanner (flanner@umich.edu)

Received: 30 December 2011 - Published in Atmos. Chem. Phys. Discuss.: 20 January 2012

Revised: 8 May 2012 - Accepted: 10 May 2012 - Published: 30 May 2012

\begin{abstract}
Here we explore light absorption by snowpack containing black carbon (BC) particles residing within ice grains. Basic considerations of particle volumes and $\mathrm{BC} /$ snow mass concentrations show that there are generally $0.05-10^{9} \mathrm{BC}$ particles for each ice grain. This suggests that internal $\mathrm{BC}$ is likely distributed as multiple inclusions within ice grains, and thus the dynamic effective medium approximation (DEMA) (Chýlek and Srivastava, 1983) is a more appropriate optical representation for $\mathrm{BC} /$ ice composites than coated-sphere or standard mixing approximations. DEMA calculations show that the $460 \mathrm{~nm}$ absorption cross-section of $\mathrm{BC} /$ ice composites, normalized to the mass of $\mathrm{BC}$, is typically enhanced by factors of 1.8-2.1 relative to interstitial $\mathrm{BC}$. $\mathrm{BC}$ effective radius is the dominant cause of variation in this enhancement, compared with ice grain size and BC volume fraction. We apply two atmospheric aerosol models that simulate interstitial and within-hydrometeor BC lifecycles. Although only $\sim 2 \%$ of the atmospheric BC burden is cloud-borne, $71-83 \%$ of the BC deposited to global snow and sea-ice surfaces occurs within hydrometeors. Key processes responsible for within-snow $\mathrm{BC}$ deposition are development of hydrophilic coatings on BC, activation of liquid droplets, and subsequent snow formation through riming or ice nucleation by other species and aggregation/accretion of ice particles. Applying deposition fields from these aerosol models in offline snow and sea-ice simulations, we calculate that $32-73 \%$ of BC in global surface snow resides within ice grains. This fraction is smaller than the within-hydrometeor deposition fraction because meltwater flux preferentially removes internal $\mathrm{BC}$, while sublimation and freezing within snowpack expose internal BC. Incorporating the DEMA into a global climate model, we simulate increases in $\mathrm{BC} /$ snow
\end{abstract}

radiative forcing of $43-86 \%$, relative to scenarios that apply external optical properties to all BC. We show that snow metamorphism driven by diffusive vapor transfer likely proceeds too slowly to alter the mass of internal $\mathrm{BC}$ while it is radiatively active, but neglected processes like wind pumping and convection may play much larger roles. These results suggest that a large portion of $\mathrm{BC}$ in surface snowpack may reside within ice grains and increase $\mathrm{BC} /$ snow radiative forcing, although measurements to evaluate this are lacking. Finally, previous studies of $\mathrm{BC} /$ snow forcing that neglected this absorption enhancement are not necessarily biased low, because of application of absorption-enhancing sulfate coatings to hydrophilic $\mathrm{BC}$, neglect of coincident absorption by dust in snow, and implicit treatment of cloud-borne $\mathrm{BC}$ resulting in longer-range transport.

\section{Introduction}

Several recent modeling studies have estimated the global radiative forcing caused by black carbon (BC) deposited to snow and sea-ice (Hansen and Nazarenko, 2004; Jacobson, 2004; Hansen et al., 2005; Flanner et al., 2007, 2009; Koch et al., 2009a; Rypdal et al., 2009; Skeie et al., 2011). Sources of uncertainty and variability in this forcing include the distribution of BC deposition, particle optical properties, ice effective grain size, meltwater scavenging efficiency, snow coverage, and coincident absorption by other impurities such as dust (e.g., Flanner et al., 2007). The absorptivity of BC is governed by its refractive index, shape, porosity, and mixing state with other material (e.g., Bohren and Huffman, 1983), and varies by roughly 2 -fold depending on whether it resides 
within or external to ice grains (e.g., Chýlek et al., 1983). Of global BC/snow studies, only Jacobson (2004) considered internal BC/ice mixing, achieved by partitioning $\mathrm{BC}$ into components residing external to ice grains and as large individual cores enclosed by ice shells. Some studies have treated hydrophilic BC as sulfate-coated (Flanner et al., 2007, 2009; Aoki et al., 2011; Yasunari et al., 2011), producing a 50\% increase in mass-normalized absorption that may mimic the effect of ice coatings. However, no global studies have included the influence of polydisperse BC within ice grains, a more realistic scenario explored here.

\subsection{Enhanced absorption}

It has been known for considerable time that light-absorbing particles can absorb more radiation when they are mixed or coated with weakly-absorbing material (e.g., Maxwell Garnett, 1904; Ackerman and Toon, 1981). This happens for multiple reasons. The mass absorption cross-section $\left(k_{\mathrm{a}}\right.$, or specific absorption cross-section) of a small particle increases with increasing refractive index $(m)$ of the bulk medium surrounding it (Bohren and Huffman, 1983; Bohren, 1986). For example, $550 \mathrm{~nm} k_{\mathrm{a}}$ of a BC particle with radius $20 \mathrm{~nm}$ and refractive index $m=1.95+0.79 i$ is $52 \%$ larger when residing in ice $\left(m=1.31+2.3 \times 10^{-9} i\right)$ than air. (Mie solutions show, however that $\partial k_{\mathrm{a}} / \partial m$ becomes smaller or negative with larger particle sizes and refractive index of the medium). Internal reflections also increase actinic flux within weakly-absorbing particles. Because of these effects, the photon density within a spherical host is roughly proportional to the square of its refractive index (Fuller et al., 1999). Additionally, radiation is focused near the center of weakly-absorbing spheres (Ackerman and Toon, 1981; Bohren, 1986), enabling further absorption enhancement from inclusions that happen to reside near the center of the composite. Internally-mixed constituents may exist as solitary or multiple inclusions. The former may be represented with coated-sphere or eccentric spherical inclusion models (e.g., Videen et al., 1994; Fuller, 1995), while the latter is better approximated with effective medium models.

Numerous studies have explored the optics of BC residing within cloud droplets and ice particles (e.g., Danielsen et al., 1969; Chýlek et al., 1984, 1996; Fuller, 1995; Videen and Chýlek, 1998; Chuang et al., 2002; Jacobson, 2006; Liou et al., 2011), with mean estimates of absorption enhancement ranging from factors of 1.5-3, depending on the hydrometeor size and shape, inclusion optical properties, inclusion size distribution, spatial distribution of inclusions within the hydrometeor, and model representation. Although enhancement can exceed a factor of 20 for inclusions near the droplet surface and along certain axes relative to incident light, orientation-averaged enhancement for nearsurface inclusions is actually smaller than that for randomlyor centrally-located inclusions (Chýlek et al., 1996; Fuller et al., 1999). Warren (1982) recognized that internal BC/ice mixing would increase absorption by snowpack, but acknowledged a lack of measurements showing that a substantial portion of BC exists within snow grains. Chýlek et al. (1984) applied the dynamic effective medium approximation (DEMA) developed by Stroud and Pan (1978) and Chýlek and Srivastava (1983) to quantify absorption by BC within snow grains, which have diameters 1-2 orders of magnitude larger than cloud hydrometeors. For an ice grain radius of $100 \mu \mathrm{m}$ and monodisperse BC size distribution, they calculated an absorption enhancement factor of about 1.7 for realistic $\mathrm{BC}$ volume fractions, and cited $\mathrm{BC}$ particle size distribution as the largest source of uncertainty, a result we reaffirm here. Liou et al. (2011) explored the optical properties of solitary BC inclusions within three different ice habits, showing an average absorption enhancement of about 1.9 that was insensitive to ice shape. Particles attached to the outside of weakly-absorbing spheres cause enhancements that are negligible to weak $(\sim 1.0-1.3)$ (e.g., Fuller et al., 1999; Liou et al., 2011).

The DEMA, a type of extended effective medium approximation, accommodates, within limits described later, randomly-located internal inclusions with any size distribution and number concentration. Thus it is more flexible than the coated-sphere (single inclusion) model or MaxwellGarnett and Bruggeman mixing approximations, which assume homogeneous mixing of inclusions at the infinitesimal scale. With this flexibility the DEMA can more accurately describe the expected $\mathrm{BC} /$ ice mixing state, which is of multiple BC inclusions (potentially of different sizes) contained within individual ice grains. Here, we build on Chýlek et al. (1984) by (1) applying the DEMA to quantify absorption enhancement over broad ranges of ice and BC size distributions expected for snowpack, (2) using these optical calculations in a column snow radiation model, and (3) incorporating a parameterization of the DEMA into a global snow/aerosol/climate model to quantify the enhancement in radiative forcing caused by internal $\mathrm{BC} /$ ice mixing.

\subsection{Mechanisms for $\mathrm{BC}$ inclusion in ice crystals}

The net influence on radiative forcing caused by this enhancement obviously depends on the proportion of $\mathrm{BC}$ that exists internal to ice grains, but there are very few snowpack measurements to inform on this. Observations have found hundreds to thousands of solid aerosol particles within and attached to falling snow crystals at the south pole (Kumai, 1976) and Sapporo Japan (Magono et al., 1979). Aerosols collected at the south pole were mostly clay minerals, whereas those in Japan were believed to be largely "carbon black" and also dust. Aoki et al. (2000) examined ice grains collected in a snowpack near Hokkaido Japan with a scanning electron microscope (SEM) and reported that most of the impurities existed external to the snow grains. Based on the vertical profiles of impurities and snowfall timeseries, however, they also concluded that most impurities 


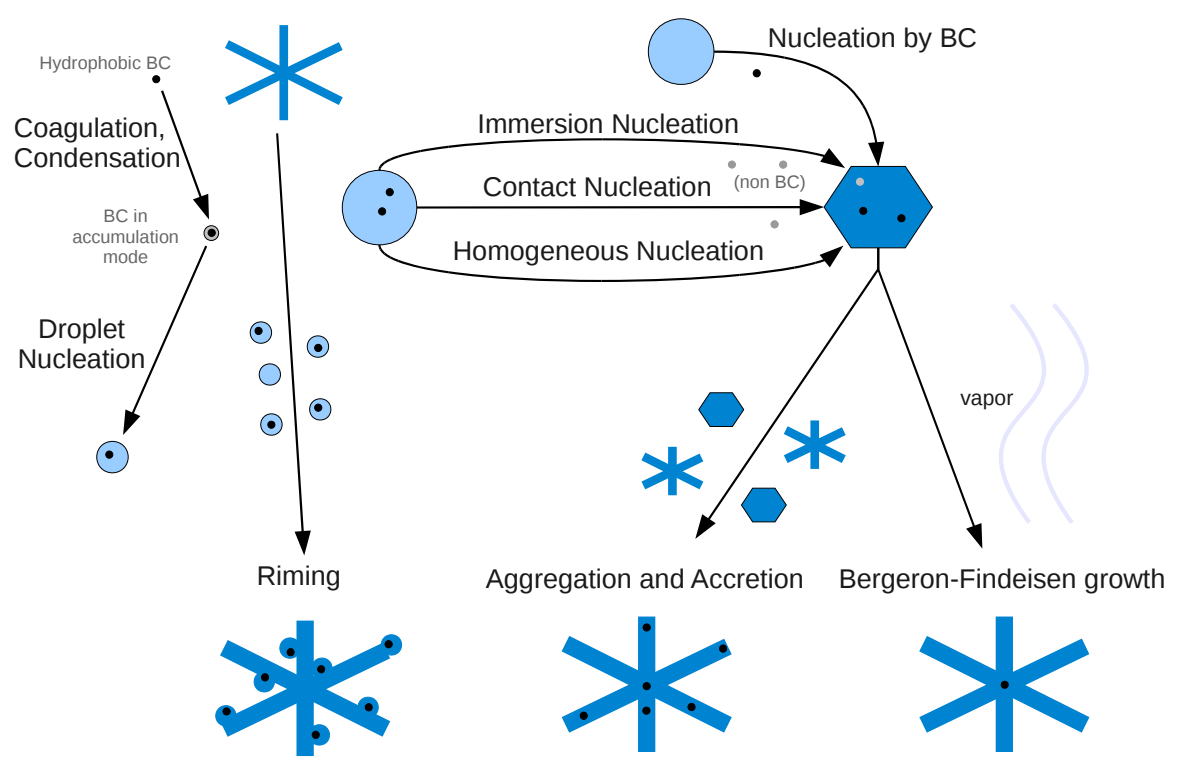

Fig. 1. Schematic of mechanisms by which black carbon can enter into precipitating ice hydrometeors. Light blue indicates super-cooled water droplets and darker blue indicates ice. Sizes are not drawn to scale.

were deposited through dry processes (and hence externally to snow grains), which is expected given the proximity of BC and soil dust sources to the measurement site. Spaulding et al. (2011), also using an SEM, observed large insoluble impurities, likely originating from dust, within firn/ice grains 30$90 \mathrm{~m}$ deep in Antarctic ice cores. Cullen and Baker (2001) and Rosenthal et al. (2007) have observed ring-like filaments on the boundaries between snow grains, but these do not appear to be related to $\mathrm{BC}$.

$\mathrm{BC}$ can enter into ice hydrometeors through several different mechanisms, as depicted in Fig. 1. Like most particles, BC nucleates ice very poorly via direct deposition of vapor (e.g., Dymarska et al., 2006), so most relevant mechanisms involve liquid water. Most emitted BC is hydrophobic (e.g., Niessner et al., 1990) and hence a poor nucleator of cloud droplets. Observations show, however, that BC rapidly "ages" through condensation of sulfuric acid and semi-volatile organics on the $\mathrm{BC}$ particle, and through coagulation with other (BC and non-BC) aerosols. Very thin coatings of condensed sulfate dramatically increase the hygroscopicity of the particle and allow it to activate cloud hydrometeors. After cloud droplets are nucleated by aged BC and other species, they can freeze through several mechanisms. First, droplets with sizes typical of those in clouds will freeze homogeneously when the air cools to around $-40^{\circ} \mathrm{C}$ (e.g., Rogers and Yau, 1994). Second, droplets freeze through heterogeneous ice nucleation at much warmer temperatures. In contact nucleation, particles encounter supercooled droplets through Brownian diffusion and initiate freezing upon contact with the surface of the droplet. Efficient ice contact nucleators include certain dust minerals (e.g., kaolinite), metal oxides, bacteria species, and organic molecules (e.g., cholesterol) (e.g. Houghton, 1985). Inefficient contact nucleation by $\mathrm{BC}$ may be partially compensated for by relatively large number concentrations. In immersion nucleation, supercooled droplets freeze after a nucleator encounters and becomes immersed within the droplet. $\mathrm{BC}$ may act as an ice immersion nucleator (DeMott et al., 1999; Gorbunov et al., 2001; Möhler et al., 2005; Liu and Penner, 2005), although there is still considerable uncertainty regarding this. Aircraft measurements have found carbonaceous material acting as ice nucleators (Chen et al., 1998) and laboratory studies indicate that sulfate-coated $\mathrm{BC}$ nucleates ice at temperatures warmer than $-40^{\circ} \mathrm{C}$ and at lower relative humidity than that needed for homogeneous nucleation of pure sulfuric acid (DeMott et al., 1999; Möhler et al., 2005), suggesting a relatively more important role for the sulfate-coated BC. Biomass burning aerosols, however, are found to be poor heterogeneous ice nucleators at temperatures between -45 and $-60^{\circ} \mathrm{C}$ (DeMott et al., 2009). In summary, heterogeneous ice nucleation by non-BC aerosols may entrain much more $\mathrm{BC}$ into ice (by freezing droplets already containing $\mathrm{BC}$ ) than mechanisms where $\mathrm{BC}$ serves as the source of ice nucleation.

Cloud ice crystals containing BC become part of ice precipitation through aggregation of ice crystals, accretion by existing snowflakes and ice hydrometeors, and by diffusive vapor growth through the Bergeron-Findeisen process, where ice crystals grow at the expense of liquid droplets because of the phase dependency of saturation vapor pressure. Liquid cloud droplets containing $\mathrm{BC}$ can also become part of ice precipitation through homogeneous freezing of raindrops and through riming, where snow crystals contact supercooled droplets, causing them to freeze on the ice hydrometeor. 
Of these processes, riming, aggregation, and accretion may cause multiple $\mathrm{BC}$ inclusions to exist within a single precipitation hydrometeor because they merge tens to thousands of cloud hydrometeors into a single particle. Conversely, ice crystals grown into snowflakes through the BergeronFindeisen process may only contain solitary inclusions, since growth occurs through vapor diffusion. Observations suggest this process plays an important role in some mixed-phase clouds (e.g. Cozic et al., 2007). Hegg et al. (2011) provide, along with informative discussion on $\mathrm{BC}$ deposition processes, strong observational evidence that riming is the primary cause for high $\mathrm{BC}$ washout from mixed-phase clouds over Svalbard during spring. BC deposition also occurs external to precipitation hydrometeors. This occurs through (1) dry deposition processes (sedimentation and turbulent mixout), often the dominant sink of large particles near to emission sources, and (2) below-cloud scavenging, where particles are collected by falling hydrometeors through Brownian motion, electrostatic forces, collision and impaction, but remain attached to the outside of the hydrometeors rather than becoming internalized. Magono et al. (1979) measured very large concentrations of attached aerosols on snowflakes $\left(\sim 10^{8}\right.$ particles per $\mathrm{cm}^{2}$ of ice surface) and 2-fold higher aerosol concentrations within rimed snow crystals, suggestive of both in-cloud and below-cloud scavenging. Here, we apply two global atmosphere/aerosol models that represent, with varying degrees of complexity, the activation and precipitation processes described above.

Finally, snowpack processes alter the $\mathrm{BC} /$ ice mixing state following surface deposition. Meltwater, in all likelihood, preferentially carries away internal impurities because they are more likely to be hydrophilic and in contact with the water. Within snowpack, $\mathrm{H}_{2} \mathrm{O}$ molecules continuously sublimate from and re-deposit to snow grains (e.g., Sturm and Benson, 1997). Sublimation exposes internal impurities, whereas vapor deposition does not encase $\mathrm{BC}$ because the saturation vapor pressure of $\mathrm{H}_{2} \mathrm{O}$ over ice is much lower than over BC. Freezing of liquid water may also exclude impurities contained within the water. All of these processes should decrease the amount of internal $\mathrm{BC}$ with time, but their impacts on radiative forcing depend both on their rates and on the local snowfall rate, since $\mathrm{BC}$ only exerts a significant radiative impact while it is near the surface. We explore these processes with global sensitivity studies.

After describing our methods (Sect. 2), we discuss the sensitivity of light absorption by BC/ice composites to particle size distributions, volume fraction, and mixing approximation (Sects. 3.1-3.5). We then apply optical properties derived from the DEMA to quantify column albedo changes using a radiative transfer model (Sect. 3.6). We conclude with results from global sensitivity studies (Sects. 3.7-3.8), finding an enhancement in $\mathrm{BC} /$ snow radiative forcing of 32-73\% due to internal mixing with ice. Finally, we note that this study focuses on $\mathrm{BC}$, but many of the concepts also apply to mineral dust, which dominates snowpack light absorption in some environments (e.g., Painter et al., 2010).

\section{Methods}

\subsection{Optical properties}

We calculate $\mathrm{BC}$ and ice particle optical properties using several different techniques. We apply the Mie and coatedsphere (or core-shell) approximations published by Bohren and Huffman (1983) (routines BHMIE and BHCOAT) to derive extinction, scattering and absorption efficiencies, and scattering asymmetry parameters. We apply different effective medium approximations to produce refractive indices for $\mathrm{BC} /$ ice aggregates that we then use with BHMIE to produce particle optical properties.

The dynamic effective medium approximation (DEMA) (Stroud and Pan, 1978; Chýlek and Srivastava, 1983) treats polydisperse, randomly-located internal inclusions of any size distribution. Chýlek and Srivastava (1983) developed unique frameworks for representing this polydispersion either as an aggregate structure (isolated inclusions) or as separated grains (layered spheres), and show that these representations can simplify, respectively, to the Bruggeman and Maxwell-Garnett effective approximations in the case of infinitesimally small inclusions. In general, effective medium approximations are only applicable when:

$\left|\frac{m_{n} 2 \pi r}{\lambda}\right| \ll 1$

where $m_{n}$ is the complex refractive index of the inclusion, $r$ is the inclusion radius, and $\lambda$ is the wavelength of interacting radiation. This criteria is not met for typical BC sizes. Extended effective medium approximations, such as the DEMA, can be applied to situations where $\left|m_{n} 2 \pi r\right|$ approaches $\lambda$, therefore accommodating inclusions that are of similar size as $\lambda$ (Mishchenko et al., 2000). Most BC particles are small enough to fall within the extended domain of applicability, but many of the dust particles in typical size distributions do not. Inclusions of similar size as $\lambda$ can produce magnetic dipoles and a composite relative permeability $(\mu)$ different from one, introducing errors in composite refractive index and Mie calculations that assume permeability of free space (Bohren, 1986). Subsequent studies, however, showed that the DEMA more accurately predicts the absorption efficiency of small water droplets containing $\mathrm{BC}$ inclusions than the Maxwell-Garnett and Bruggeman approximations, when compared with exact theoretical solutions for single arbitrarily-located inclusions (Videen et al., 1994), and when compared against calculations with a discrete dipole approximation for multiple $\mathrm{BC}$ inclusions (Mishchenko et al., 2000).

Chýlek et al. (1983) recommend the aggregate structure framework as more appropriate for $\mathrm{BC}$ in snow because the 
inclusions are more likely to be separated from one another at low volume fractions. In this case, the effective dielectric constant of the composite $(\epsilon)$ can be solved for iteratively with the following set of equations (Chýlek et al., 1983, 1984; Videen and Chýlek, 1998):

$\epsilon=\epsilon_{\mathrm{m}} \frac{A(1-V)+B(\epsilon)}{A(1-V)-2 B(\epsilon)}$

where:

$A(\epsilon)=i \frac{12 \pi^{2}}{\lambda^{3}} \epsilon^{3 / 2}$

and

$B(\epsilon)=\int \sum_{p}(2 p+1)\left[a_{\mathrm{p}}\left(r, \epsilon_{\mathrm{b}} / \epsilon\right)+b_{\mathrm{p}}\left(r, \epsilon_{\mathrm{b}} / \epsilon\right)\right] N(r) d r$

Here, $V$ is the volume fraction of the inclusions, $\epsilon_{\mathrm{m}}$ is the dielectric constant of the matrix (ice, in our case), $\epsilon_{\mathrm{b}}$ is the dielectric constant of the inclusions (BC) and $a_{\mathrm{p}}\left(r, \epsilon_{\mathrm{b}} / \epsilon\right)$ and $b_{\mathrm{p}}\left(r, \epsilon_{\mathrm{b}} / \epsilon\right)$ are the Mie partial wave scattering terms for inclusions with radius $r$ and dielectric constant $\epsilon_{\mathrm{b}}$, residing in the composite (ice $+\mathrm{BC}$ ) material characterized with $\epsilon$. Solutions for $a_{\mathrm{p}}$ and $b_{\mathrm{p}}$ are obtained iteratively with BHMIE. The inclusion number concentration is $N(r)$ (units of $\#^{-3}$ per radius interval $d r$, or $\#^{-4}$ ), and is thus related to the volume fraction $V$ as:

$V=4 \pi / 3 \int N(r) r^{3} d r$

The inclusion size parameter $(x)$, also needed for solutions of $a_{\mathrm{p}}$ and $b_{\mathrm{p}}$, is:

$x=2 \pi r n_{\mathrm{m}} / \lambda$

where $n_{\mathrm{m}}$ is the real component of the matrix refractive index. The choice of $p$ should be larger than the size parameter $x$, where Bohren and Huffman (1983) suggest $p=x+4 x^{1 / 3}+2$. We apply a secant method to iteratively solve Eqs. (2-4), and typically converge to within $10^{-12}$ of equality with 8 iterations or less. In the limit of infinitesimally small inclusions $(r \rightarrow 0)$, the solution for $\epsilon$ reduces to the Bruggeman approximation, as shown by Chýlek et al. (1984):

$(1-V) \frac{\epsilon_{\mathrm{m}}-\epsilon}{\epsilon_{\mathrm{m}}+2 \epsilon}+V \frac{\epsilon_{\mathrm{b}}-\epsilon}{\epsilon_{\mathrm{b}}+2 \epsilon}=0$

We also applied the Maxwell-Garnett mixing approximation, but over the domains explored in this study we found such close agreement between the Maxwell-Garnett and Bruggeman approximations that we only report Bruggeman solutions. This is a general outcome for cases with small inclusions and volume fractions (Bohren and Huffman, 1983).
We report several results in terms of the effective mass absorption cross-section of internally-mixed $\mathrm{BC}\left(k_{\mathrm{bc}, \text { int }}\right)$, which we define as:

$k_{\mathrm{bc}, \text { int }}=\frac{\sigma_{\mathrm{bi}}-\sigma_{\mathrm{i}}}{M_{\mathrm{bc}}}$

where $\sigma_{\mathrm{bi}}$ is the absorption cross-section of a composite particle containing ice and $\mathrm{BC}, \sigma_{\mathrm{i}}$ is the absorption cross-section of a pure ice particle with equal size (and shape) as the composite, $M_{\mathrm{bc}}$ is the mass of $\mathrm{BC}$ within the composite particle, and we have dropped the usual absorption subscript $a$ for economy. For small mass fractions of internally-mixed BC, or situations with similar inclusion and matrix densities:

$k_{\mathrm{bc}, \mathrm{int}} \approx \frac{k_{\mathrm{bi}}-k_{\mathrm{i}}}{f}$

where $k_{\mathrm{bi}}$ is the mass absorption cross-section of a composite ice/BC particle (normalized to the combined mass of $\mathrm{BC}$ and ice), $k_{\mathrm{i}}$ is the absorption cross-section of an equalsized pure-ice particle, and $f$ is the mass fraction of $\mathrm{BC}$ : $M_{\mathrm{bc}} /\left(M_{\mathrm{bc}}+M_{\mathrm{ice}}\right)$. We also report results in terms of an enhancement ratio $(E)$, which we define as the ratio of $k_{\mathrm{bc}, \text { int }}$ to $k_{\mathrm{bc}, \mathrm{ext}}$ for identical BC size distributions:

$E\left(r_{\mathrm{bc}}, r_{\mathrm{ice}}, V\right)=\frac{k_{\mathrm{bc}, \text { int }}\left(r_{\mathrm{bc}}, r_{\mathrm{ice}}, V\right)}{k_{\mathrm{bc}, \text { ext }}\left(r_{\mathrm{bc}}\right)}$

Here, we characterize the size distribution of $\mathrm{BC}$ inclusions with the effective radius, or surface-area weighted mean radius, of lognormal size distributions. Although the DEMA accommodates any inclusion size distribution, including the gamma distributions originally used by Chýlek et al. (1983), more recent measurements characterize BC size distributions with lognormal functions (e.g., Bond et al., 2006b).

\subsection{Global simulations}

To study the influence of BC/ice mixing state on snow radiative forcing, we apply two global atmospheric aerosol models to simulate and resolve the deposition of interstitial and within-hydrometeor BC. We then prescribe these deposition fields in "offline" versions of the Community Land Model (CLM) and sea-ice (CICE) components of the National Center for Atmospheric Research (NCAR) Community Earth System Model (CESM) version 1.0.3 (Gent et al., 2011). CLM includes the Snow, Ice, and Aerosol Radiative (SNICAR) sub-model (Flanner et al., 2007, 2009; Oleson et al., 2010), which we use to treat radiative effects of snowdeposited BC and other aerosols. Aerosol transport and radiative influence within CICE are described by Holland et al. (2012) and Briegleb and Light (2007). These offline snow and sea-ice simulations facilitate deposition fields generated from multiple aerosol models, and are also much less computationally expensive than coupled atmosphere-land-sea-ice 
simulations, enabling more sensitivity studies to be conducted (i.e., with varying $\mathrm{BC}$ size distributions and snowpack processes).

We employ two aerosol models: (1) the modal aerosol model MAM7 (Liu et al., 2012), which is embedded in the Community Atmosphere Model (CAM 5.1) component of CESM, and (2) the University of Michigan IMPACT model. MAM7 resolves seven lognormal aerosol modes, keeping track of particle number concentration in each mode and internally-mixed mass concentrations of BC, sulfate, sea salt, primary and secondary organic matter, soil dust, and ammonium. In MAM7-CAM5, aerosols interact with clouds through activation, transport, aqueous chemistry, and resuspension, thereby influencing the aerosol amounts that exist interstitially and within cloud hydrometeors (Easter et al., 2004; Ghan and Easter, 2006; Morrison and Gettelman, 2008; Liu et al., 2012). IMPACT simulates mass and number of pure sulfate aerosol in 3 modes, BC and organic matter in a single sub-micron mode, and dust and sea salt in 4 size bins (Liu et al., 2005; Wang et al., 2009). Thus, 12 separate or externally mixed aerosol types/sizes are followed. We applied an offline configuration of IMPACT (Zhou et al., 2012) forced with hourly atmospheric states generated from two atmosphere models: the Geophysical Fluid Dynamics Laboratory (GFDL) Atmosphere Model 3 (AM3) (Donner et al., 2011) and CAM5. These prescribed atmospheric states (including a variety of cloud, precipitation, and dynamical tendencies) influence aerosol microphysics and cloud-borne/interstitial aerosol partitioning within IMPACT. Both atmospheric states were generated using climatological SSTs. We conducted two offline aerosol simulations (IMPACT-AM3 and IMPACT-CAM5) each for two years and applied the final year of BC deposition data in this study. The MAM7-CAM5 coupled atmosphere/aerosol simulation also applied present-day climatological SSTs and was run for $4 \mathrm{yr}$, with the final three years averaged to obtain monthly-mean gridded surface deposition fields.

In the CLM and CICE simulations driven with these deposition fields, the surface-deposited masses of interstitial and within-hydrometeor BC enter the snowpack as, respectively, externally- and internally-mixed BC with respect to snow grains. The concentrations of each species within each snow and sea-ice layer depend on deposition rates, new snowfall, ice sublimation, meltwater flushing, and layer combinations and divisions (Flanner et al., 2007; Oleson et al., 2010; Holland et al., 2012). For radiative purposes, these models treat the snow/ice as an external mixture of pure ice grains, two species of $\mathrm{BC}$, and four species of dust. We scale $k_{\mathrm{bc}}$ of the internally-mixed $\mathrm{BC}$ by an enhancement ratio (Eq. 10) dependent on $\mathrm{BC}$ and snow effective radii, derived from offline DEMA calculations described below, and retrieved online via a lookup table. Application of the enhancement ratio is justified later as a reasonable approach to account for altered snowpack radiative transfer caused by internal mixing. A more realistic approach, but one which is less feasi- ble for GCM application because of the large number of advected species required, is to treat the snowpack as an external mixture of pure ice particles, interstitial aerosols, and numerous BC-ice composite species. The number of composite species would need to be large enough to span the variability in ice effective radius, inclusion size distribution and type, and internal volume fraction simulated by the model. This approach is adopted for offline radiative transfer calculations discussed in Sect. 3.6, which shows that $k_{\mathrm{bc} \text {,int }}$ and $k_{\mathrm{bc} \text {,ext }}$ are good predictors of the change in snowpack albedo caused by BC, regardless of its mixing state with ice. Yet another approach could be to treat volume mixing of ice and multiple internally-mixed aerosol species in different size modes or bins, as done for optical treatment of hydrated aerosols in the atmosphere model (Ghan and Zaveri, 2007). In all experiments, dust is radiatively active and hence decreases the forcing by BC (Flanner et al., 2009). Accounting for enhanced absorption by internally-mixed dust, however, could further decrease BC forcing.

In MAM7-CAM5, all BC is emitted into the primary carbon mode, which also includes primary organic matter $(\mathrm{POM}) . \mathrm{BC}$ ages into the accumulation mode through condensation of $\mathrm{H}_{2} \mathrm{SO}_{4}$ and semi-volatile organics, and also through coagulation of aerosols between the Aitken, primary carbon, and accumulation modes (Seinfeld and Pandis, 1998). We apply two modifications described by Liu et al. (2012) that improved the simulated atmospheric BC distribution in remote regions like the Arctic, relative to observations (Schwarz et al., 2010). These modifications are: (1) increasing the threshold from 3 to 8 monolayers of sulfateequivalent coating on $\mathrm{BC}$ for it to transfer from the primary carbon mode to the accumulation mode, and (2) decreasing the hygroscopicity of POM from 0.1 to 0.0 , which eliminates wet scavenging of primary carbon mode BC (because of internal mixing with $\mathrm{POM}$ ). Both changes reduce the fraction of $\mathrm{BC}$ residing within cloud hydrometeors, reduce the portion of atmospheric $\mathrm{BC}$ subject to wet deposition, and increase the atmospheric residence time of BC. Once in the accumulation mode, aerosols become activated and subject to stratiform in-cloud scavenging based on the local hygroscopicity and size distribution of the mode, and ambient temperature, pressure, and supersaturation (Abdul-Razzak and Ghan, 2000). Once it has transferred to the accumulation mode, mixing with ambient sulfate, ammonium, organic matter and sea-salt increases the activation rate of BC. In clouds at temperatures between $-37^{\circ}$ and $0{ }^{\circ} \mathrm{C}$, ice nucleation of liquid droplets, which may contain $\mathrm{BC}$ through the activation described above, depends on temperature and supersaturation (Meyers et al., 1992). In clouds colder than $-37^{\circ} \mathrm{C}$, ice nucleation follows Liu et al. (2007) and Liu and Penner (2005), which includes homogeneous nucleation of sulfate and heterogeneous immersion nucleation caused by mineral dust. In IMPACT, the amount of BC residing within hydrometeors is governed by its scavenging efficiency. This depends on temperature and the amount of sulfate accumulated on its 
Table 1. Enhancement in BC/snow radiative forcing due to internal mixing with ice. Paired control simulations apply external BC optical properties to all BC.

\begin{tabular}{lcccc}
\hline \multirow{2}{*}{ Model } & \multicolumn{3}{c}{ BC effective radius [nm] } \\
\cline { 2 - 5 } & 50 & 100 & 150 & 250 \\
\hline MAM7-CAM5, Rslow & $+63 \%$ & $+66 \%$ & $+73 \%$ & $+86 \%$ \\
MAM7-CAM5, Rfast & $+60 \%$ & $+63 \%$ & $+70 \%$ & $+82 \%$ \\
MAM7-CAM5, Rfast + sub & $+54 \%$ & $+56 \%$ & $+62 \%$ & $+73 \%$ \\
MAM7-CAM5, Rfast + sub + frz & $+43 \%$ & $+45 \%$ & $+49 \%$ & $+57 \%$ \\
\hline IMPACT-AM3, Rslow & $+58 \%$ & $+61 \%$ & $+67 \%$ & $+79 \%$ \\
IMPACT-AM3, Rfast & $+54 \%$ & $+57 \%$ & $+63 \%$ & $+75 \%$ \\
IMPACT-AM3, Rfast+sub & $+49 \%$ & $+52 \%$ & $+57 \%$ & $+68 \%$ \\
IMPACT-AM3, Rfast+sub+frz & $+40 \%$ & $+42 \%$ & $+46 \%$ & $+54 \%$ \\
\hline IMPACT-CAM5, Rslow & $+51 \%$ & $+53 \%$ & $+58 \%$ & $+69 \%$ \\
IMPACT-CAM5, Rfast & $+46 \%$ & $+49 \%$ & $+53 \%$ & $+63 \%$ \\
IMPACT-CAM5, Rfast + sub & $+41 \%$ & $+43 \%$ & $+48 \%$ & $+56 \%$ \\
IMPACT-CAM5, Rfast + sub + frz & $+34 \%$ & $+35 \%$ & $+39 \%$ & $+45 \%$ \\
\hline
\end{tabular}

surface via the following three processes: (1) condensation of gaseous $\mathrm{H}_{2} \mathrm{SO}_{4}$, (2) sulfate produced by aqueous phase oxidation of $\mathrm{SO}_{2}$ on the surface, and (3) coagulation with pure sulfate aerosols. Above $0{ }^{\circ} \mathrm{C}$, the $\mathrm{BC}$ scavenging efficiency increases linearly from 0 to 1 as the sulfate coating thickness increases from 0 to 10 monolayers. Below $0{ }^{\circ} \mathrm{C}$, the scavenging efficiency decreases linearly from its suprafreezing value to 0.1 as the temperature decreases from $0{ }^{\circ} \mathrm{C}$ to $-40^{\circ} \mathrm{C}$, and is constant at 0.1 below $-40^{\circ} \mathrm{C}$.

Stratiform precipitation collects cloud-borne and interstitial aerosols through in-cloud and below-cloud scavenging processes in both CAM5 (Barth et al., 2000; Rasch et al., 2000; Liu et al., 2012), and IMPACT (Mari et al., 2001; Liu et al., 2001). The first-order removal rate of cloud-borne aerosols equals the first-order removal rate of cloud water/ice mass from precipitation, determined from cloud fraction and precipitation production profiles. Below-cloud scavenging removes interstitial aerosol and depends on the precipitation rate, and a size- and species-dependent wet scavenging efficiency that implictly accounts for impaction and Brownian motion. We assume that aerosols removed through belowcloud wet deposition remain in the interstitial (external) state upon deposition to snow. In CAM5, precipitation production includes riming, which can be effective at removing $\mathrm{BC}$ from mixed-phase clouds (Hegg et al., 2011). In both models, cloud-borne aerosols become re-suspended into the interstitial state through evaporation of cloud and precipitation. Both models also treat convective scavenging, but this is less relevant for determining the mixing state of $\mathrm{BC}$ deposited through snow precipitation (only $1.5 \%$ of the precipitation over snow surfaces in CAM5 is derived from convection). Although the models prognose surface deposition of cloudborne and interstitial aerosol mass, aggregation and accretion processes are not explicitly treated at the level of individual hydrometeors, meaning we do not simulate the distribution of aerosol number concentrations within the precipitating hydrometeors, which can influence total absorption (Sect. 3.5). Furthermore, because these models do not resolve the isolated size distribution of $\mathrm{BC}$, we assume different fixed size distributions of deposited $\mathrm{BC}$ in sensitivity studies designed to bracket the influence of $\mathrm{BC}$ size distribution.

Using deposition fields from MAM7-CAM5, IMPACTAM3, and IMPACT-CAM5, we conduct a series of sensitivity studies with CLM and CICE to quantify the increase in radiative forcing from internally-mixed BC in ice (results shown in Table 1). These simulations are forced with 19992004 atmospheric conditions, and the first year is excluded from analysis to enable spin-up of $\mathrm{BC}$ in the atmosphere and snow. Control simulations apply identical optical properties to internal and external $\mathrm{BC}$, whereas paired experiments apply more absorptive properties to internal BC. We run simulations with fixed $\mathrm{BC}$ effective radii of 50,100, 150, and $250 \mu \mathrm{m}$, and with four configurations of post-depositional snow processes, labeled "Rslow", "Rfast", "Rfast + sub", and "Rfast + sub + frz". The Rslow simulations apply meltwater scavenging efficiencies used previously (Flanner et al., 2007, 2009): 0.03 for external BC (analogous to hydrophobic BC) and 0.2 for internal BC (analogous to hydrophilic BC). The Rfast parameters are 0.03 and 1.0, respectively, representing 5-fold more efficient removal of internal BC with meltwater than Rslow. (A scavenging efficiency of 1 means that the mass fraction of $\mathrm{BC}$ removed from a layer equals the mass fraction of ice removed via meltwater). The Rfast+sub simulation applies Rfast scavenging parameters, and also assumes that bulk sublimation from the snowpack transfers a proportional mass of surface-layer BC from the internal to external state. Finally, Rfast + sub + frz includes the additional assumption that freezing of liquid water excludes internal BC 
from the newly-formed ice. Thus, in the Rfast + sub + frz experiment, the time derivatives of internal and external $\mathrm{BC}$ masses $\left(m_{\mathrm{b}, \mathrm{i}}\right.$ and $\left.m_{\mathrm{b}, \mathrm{e}}\right)$ in the surface snow layer with mass $m_{\mathrm{s}}$ are:

$$
\frac{d m_{\mathrm{b}, \mathrm{i}}}{d t}=D_{\mathrm{b}, \mathrm{i}}-\frac{m_{\mathrm{b}, \mathrm{i}}}{m_{\mathrm{s}}}\left(S_{\mathrm{i}} Q_{\mathrm{mlt}}+Q_{\mathrm{sub}}+Q_{\mathrm{frz}}\right)
$$

$$
\frac{d m_{\mathrm{b}, \mathrm{e}}}{d t}=D_{\mathrm{b}, \mathrm{e}}-\frac{m_{\mathrm{b}, \mathrm{e}}}{m_{\mathrm{s}}} S_{\mathrm{e}} Q_{\mathrm{mlt}}+\frac{m_{\mathrm{b}, \mathrm{i}}}{m_{\mathrm{s}}}\left(Q_{\mathrm{sub}}+Q_{\mathrm{frz}}\right)
$$

where $D_{\mathrm{b}, \mathrm{i}}$ and $D_{\mathrm{b}, \mathrm{e}}$ are the deposition fluxes of withinhydrometeor and interstitial BC, $S_{\mathrm{i}}$ and $S_{\mathrm{e}}$ are the meltwater scavenging efficiencies for internal and external BC, and $Q_{\text {mlt }}, Q_{\text {sub }}, Q_{\text {frz }}$ are, respectively, the (positive) mass fluxes of meltwater out of the layer, ice loss via sublimation to the atmosphere, and liquid water freezing within the layer. Because only the land model treats multi-layer, multi-phase snow processes, experiments Rfast+sub and Rfast + sub + frz were only conducted with CLM. For consistency, we report all forcing enhancements with respect to globally-averaged land snow forcings.

$\mathrm{BC}$ is radiatively passive in these simulations, so that differences in forcing are not caused by differences in snow state or climate. Results are reported for each experiment as the relative increase in forcing with respect to its paired control. We calculate radiative forcing each timestep as the instantaneous difference in absorbed surface energy with and without BC.

\section{Results}

\subsection{Inferred $\mathrm{BC}$ and ice grain number concentrations}

We begin by considering the implications of measured particle sizes and $\mathrm{BC}$ concentrations in snow for inclusion number concentrations. Measurements of freshly combusted BC number-median radius $\left(r_{n}\right)$ are typically in the range of 5$100 \mathrm{~nm}$, whereas aged plumes show $r_{n}$ of $50-250 \mathrm{~nm}$ (Bond et al., 2006a, Tables 3 and 4). Sources like cooking stoves can generate larger BC particles with $r_{n}$ up to $500 \mathrm{~nm}$. For lognormal size distributions with $\sigma_{\mathrm{g}}=2.0$ these ranges of $r_{n}$ correspond to volume-mean radii of $10-1000 \mathrm{~nm}$. Effective radii of snow grains, on the other hand, range from roughly 30 $2000 \mu \mathrm{m}$ (e.g., Wiscombe and Warren, 1980; Painter et al., 2003). The effective radius describes a distribution of spheres that has the same specific surface area as the ice crystals, enabling accurate radiative representation of the snow scattering and absorption (e.g., Wiscombe and Warren, 1980), but describes a volume that is much smaller than that of actual (aspherical) snow grains. The volume-equivalent sphere radius for various cylinders and hexagonal prisms that resemble atmospheric and snowpack crystals is $1.2-5$ times larger than the effective radius (e.g., Grenfell and Warren, 1999;
Neshyba et al., 2003; Grenfell et al., 2005). Considering these size ranges, the volume ratio of individual $\mathrm{BC}$ and ice particles could range from $10^{-18}$ to $2 \times 10^{-5}$. Considering more realistic ranges of volume-equivalent radii $(20-200 \mathrm{~nm}$ for BC and 200-2000 $\mu \mathrm{m}$ for snow grains), the single-particle $\mathrm{BC} /$ ice volume ratio ranges from $10^{-15}$ to $10^{-9}$. Considering aerosol size distributions measured within Arctic air masses of anthropogenic and biomass burning origin (Brock et al., 2011, Table 3), typical Arctic BC/ice volume ratios might be about $3 \times 10^{-11}$ and $10^{-13}$, respectively, in nonmelting and melting snow. Measured mass concentrations of $\mathrm{BC}$ within snowpack range from $0.1-1500 \mathrm{ng} \mathrm{g}^{-1}$, where the lowest and highest values are found, respectively, in Antarctica (Warren and Clarke, 1990) and continental areas like China (Huang et al., 2011). Bulk volume concentrations are lower than these mass concentrations by a factor of $1-2$ because of differences in density. Comparing these ranges of bulk and single-particle volume fractions, we conclude that snowpacks have, on average, between 0.05 and $10^{9} \mathrm{BC}$ particles for each ice grain. In the Arctic, this range might be between 70 and $2 \times 10^{5}$, assuming the volume ratios described above and background $\mathrm{BC} /$ snow concentrations of 3-30 ng g ${ }^{-1}$ (Doherty et al., 2010). Therefore, ice grains containing BC are likely to host numerous inclusions. Supporting evidence for this comes from micrographs of rimed snow crystals containing several thousand inclusions suspected to be black carbon (Magono et al., 1979).

\section{2 $\mathrm{BC}$ and ice properties}

We apply spectrally-varying ice refractive index data from Warren and Brandt (2008) and BC refractive indices from Chang and Charalampopoulos (1990), modified to achieve a value of $m=1.95+0.79 i$ at $\lambda=550 \mathrm{~nm}$, which is on the absorptive end of recommendations from a comprehensive review (Bond and Bergstrom, 2006). This modification was achieved by altering the linear offset term in the empirical functions listed by Chang and Charalampopoulos (1990), and allows us to retain realistic spectral variation in $\mathrm{BC}$ optical properties while matching contemporary recommendations (Bond and Bergstrom, 2006). The real ( $n$ ) and imaginary $(k) \mathrm{BC}$ refractive indices are thus calculated in terms of wavelength ( $\lambda$, in microns), over the range $0.3-5.0 \mu \mathrm{m}$, as:

$n=2.0248+0.1263 \log \lambda+0.027 \log ^{2} \lambda+0.0417 \log ^{3} \lambda$

$k=0.7779+0.1213 \log \lambda+0.2309 \log ^{2} \lambda-0.01 \log ^{3} \lambda$

We assume a BC density of $1270 \mathrm{~kg} \mathrm{~m}^{-3}$ to achieve a value of $k_{\mathrm{bc}, \text { ext }}=7.5 \mathrm{~m}^{2} \mathrm{~g}^{-1}$ at $550 \mathrm{~nm}$, which is also recommended by Bond and Bergstrom (2006). This choice was derived from Mie calculations applying the refractive indices described above and a BC size distribution with numbermedian radius of $40 \mathrm{~nm}$ (effective radius of $95 \mathrm{~nm}$ ), which is 
applied in MAM7-CAM5 for freshly-emitted BC (Liu et al., 2012). This relatively low BC density accounts for air voids and agglomeration of soot spherules, the latter of which can increase specific absorption by up to $30 \%$ relative to unagglomerated spheres used with Mie Theory (Fuller et al., 1999). Although the assumed BC density has a strong influence on $k_{\mathrm{bc}}$ (and hence radiative forcing), it has no bearing on the absorption enhancement (Eq. 10), which is determined by volume fraction, size distributions, and refractive index, and which is the focus of this paper.

Initially, we study particle absorption at a single wavelength. We choose $\lambda=460 \mathrm{~nm}$ because this is the spectral region of maximum change in snowpack absorption caused by modest amounts $\left(10-100 \mathrm{ng} \mathrm{g}^{-1}\right)$ of BC in snow. We determined this using a column snow radiation model (Flanner et al., 2007, available at: http://snow.engin.umich. edu/) and updated ice optical properties from Warren and Brandt (2008). In the blue spectrum, very weak absorption by ice combines with strong downwelling spectral irradiance to produce this maximum sensitivity. The $460 \mathrm{~nm} \mathrm{BC}$ and ice refractive indices are, respectively, $1.92+0.83 i$ and $1.32+1.33 \times 10^{-10} i$.

\subsection{Coated spheres}

Before proceeding to the DEMA, we explore the utility of the coated-sphere model (e.g., Toon and Ackerman, 1981; Bohren and Huffman, 1983). This model has been applied widely to atmospheric aerosols that have thin coatings. Jacobson (2004) also applied this model to treat BC within snow grains, but acknowledged that snow is ideally treated as ice grains containing multiple $\mathrm{BC}$ inclusions and that solitary $\mathrm{BC}$ inclusions need to be unrealistically large to account for sufficient internal mass. To reduce computational time, Jacobson (2004) assumed a constant BC core radius of $133 \mathrm{~nm}$, representative of aged coagulated BC. Based on arguments presented above, we also conclude that internal $\mathrm{BC}$ mass should be treated as multiple inclusions within ice grains. If, however, internally-mixed $\mathrm{BC}$ does characteristically exist as single particles within ice grains, then the internal mass of $\mathrm{BC}$ is likely too small to significantly impact snow radiative transfer. In either case, the utility of the coated-sphere model is marginalized. Nonetheless, solitary BC inclusions may be pervasive in ice crystals (if not comprising a large mass fraction of the total $\mathrm{BC}$ ) because of atmospheric phenomenon like the Bergeron-Findeisen process. Hence, we briefly consider optical effects associated with solitary BC inclusions in large ice spheres.

Figure 2 shows the $460 \mathrm{~nm} k_{\mathrm{bc} \text {,int }}$ (calculated with Eq. 8) of individual $\mathrm{BC}$ inclusions residing within individual ice grains. Figure 2 shows that: (1) the $\mathrm{BC}$ radius where $k_{\mathrm{bc}, \mathrm{ext}}$ peaks is about $63 \mathrm{~nm}$, smaller than the $\sim 80 \mathrm{~nm}$ peak for $550 \mathrm{~nm} k_{\mathrm{bc}, \mathrm{ext}}$ (Bond and Bergstrom, 2006); (2) the BC radius of peak absorption becomes smaller when it resides within a large ice sphere; (3) for $\mathrm{BC}$ radii greater than about

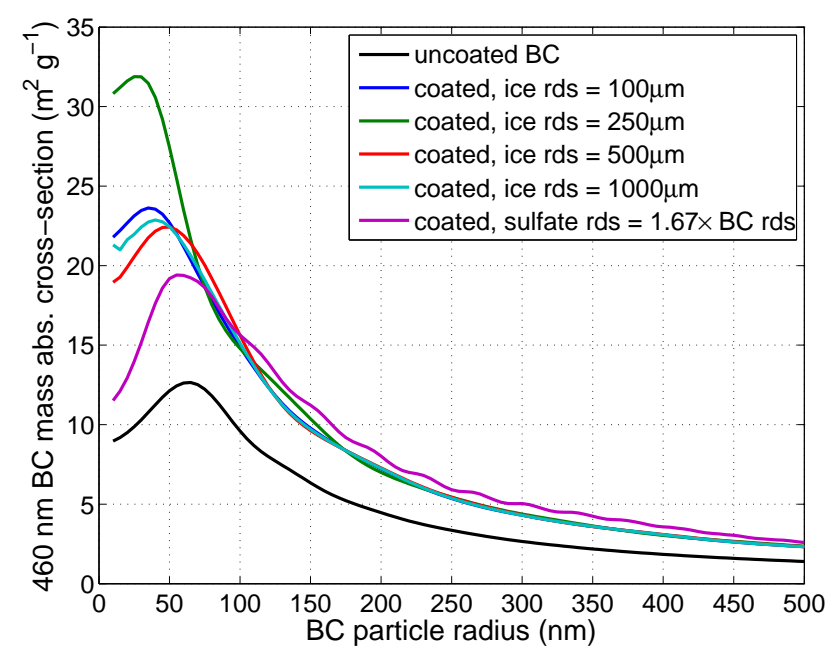

Fig. 2. The effective $460 \mathrm{~nm}$ mass absorption cross-section (Eq. 8) of solitary BC cores within ice shells of different radii, as simulated with the coated-sphere approximation (Bohren and Huffman, 1983). A curve is also shown for BC encased with a thin sulfate coating. The BC refractive index is $1.92+0.83 i$ (Eqs. 13-14).

$100 \mathrm{~nm}$, the enhancement ratio $\left(k_{\mathrm{bc}, \text { int }} / k_{\mathrm{bc}, \text { ext }}\right)$ is nearly independent of ice radius, and averages about 1.6; and (4) large enhancement ratios $(>3)$ occur within a limited domain of small BC size $(r<50 \mathrm{~nm})$ and intermediate ice size $(\sim 200$ $300 \mu \mathrm{m}$ ). Thus, the enhancement ratio does not change monotonically with ice grain size. The coated-sphere approximation cannot be applied to large absorbing particles, or specifically in conditions where the product of the size parameter and the imaginary component of the refractive index exceeds about 30 (Bohren and Huffman, 1983). For the parameters considered here, however, this criteria would only be violated for $\mathrm{BC}$ radii greater than $\sim 3 \mu \mathrm{m}$.

For comparison, a curve showing the enhancement caused by a sulfate coating with radius 1.67 times larger than the $\mathrm{BC}$ radius is also included in Fig. 2. This configuration was applied to hydrophilic BC by Flanner et al. (2007), producing an absorption enhancement of $50 \%$ at $550 \mathrm{~nm}$ (Bond et al., 2006a), and a slightly thicker sulfate shell was applied by Aoki et al. (2011). Figure 2 shows that the sulfate enhancement is less than that caused by ice for $\mathrm{BC}$ radii less than $70 \mathrm{~nm}$, and similar to the ice enhancement at larger $\mathrm{BC}$ radii, in spite of the shell thickness being several orders of magnitude smaller. For BC radii between 25 and $100 \mathrm{~nm}$, the sulfate enhancement ratio is 1.4-1.6, similar to the 1.5fold enhancement resulting from the BC size distribution applied previously (Flanner et al., 2007). It appears unrealistic, though, to assume that $\mathrm{BC}$ particles remain sulfatecoated within the snowpack because hydrophilic BC often exists, shortly before being deposited to the surface, within liquid hydrometeors where the sulfate coating presumably dissolves. Because sulfate has a larger real refractive index than ice and is weakly absorbing, a sulfate coating of equal 

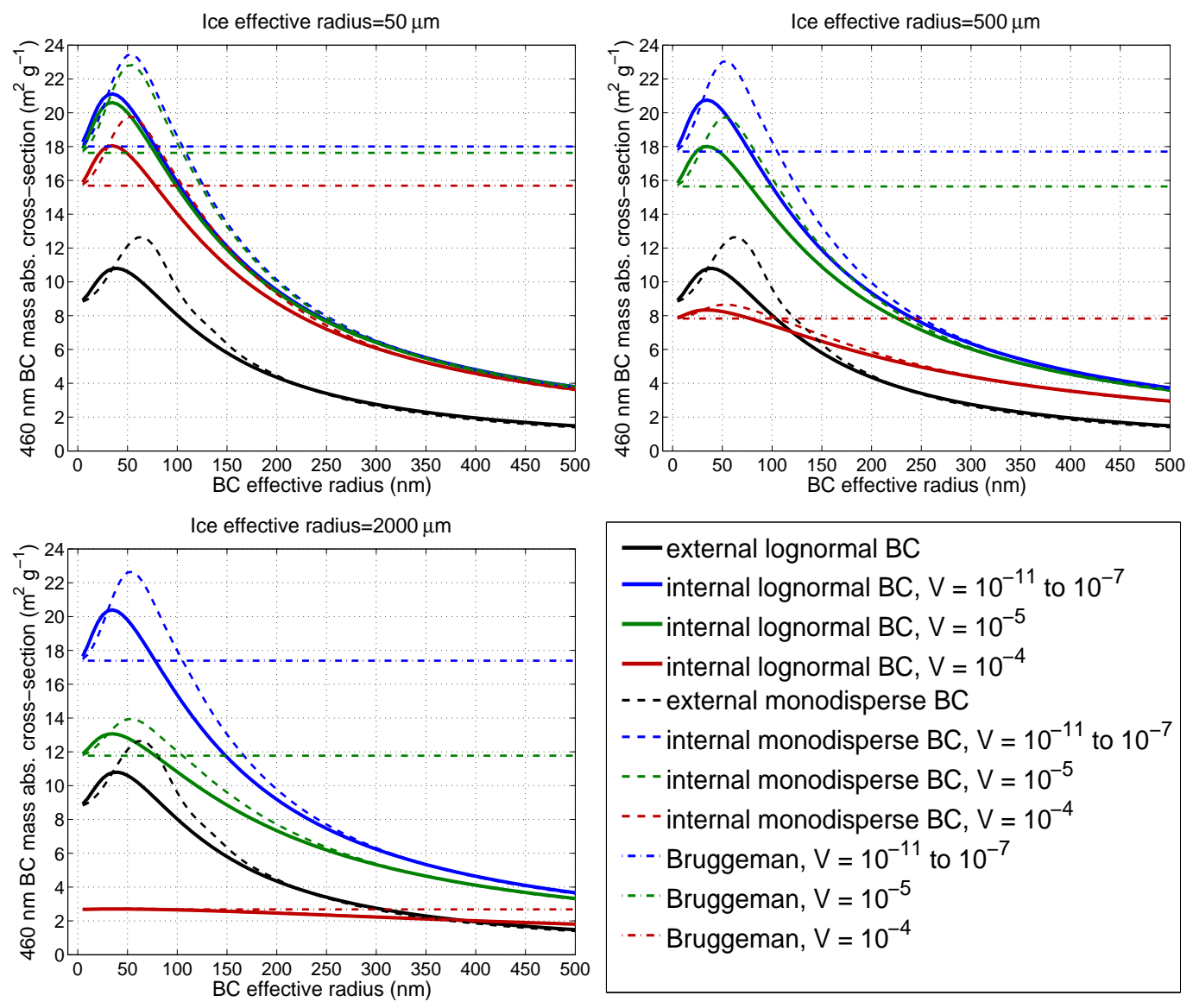

Fig. 3. The effective $460 \mathrm{~nm}$ mass absorption cross-section (Eq. 8) of BC inclusions with different size distributions and volume fractions $(V)$, embedded in ice spheres of different radii, simulated with the DEMA (Chýlek and Srivastava, 1983) and Mie calculations. Solid and dotted curves show, respectively, lognormal and monodisperse BC size distributions, expressed in terms of effective radius. The lognormal distributions have $\sigma_{\mathrm{g}}=1.8$. Curves with identical color have identical BC volume fraction. Results obtained with volume fractions between $10^{-11}$ and $10^{-7}$ are nearly identical and are depicted with single curves. Also shown are solutions from the Bruggeman approximation (dash-dot lines, with color corresponding to volume fraction), which the DEMA simplifies to as inclusion size approaches zero.

thickness produces greater absorption enhancement than ice (e.g., Fuller et al., 1999).

\subsection{Dynamic effective medium approximation}

Next we explore absorption by BC/ice composites modeled with the DEMA (Stroud and Pan, 1978; Chýlek and Srivastava, 1983; Chýlek et al., 1983), which includes the influence of internally-mixed inclusion (BC) size distributions (Eq. 4). Figure 3 shows $k_{\mathrm{bc} \text {,ext }}$ and $k_{\mathrm{bc} \text {,int }}$ as a function of $\mathrm{BC}$ radius, for different $\mathrm{BC}$ volume fractions $(V)$ and ice effective radii. Curves are shown for both monodisperse and lognormal BC size distributions, which are expressed with effective radius and have $\sigma_{\mathrm{g}}=1.8$ for consistency with global studies discussed next.

Several features are apparent in Fig. 3. As seen earlier, $k_{\mathrm{bc} \text {,ext }}$ peaks at small particle sizes (effective radius of $\sim 40 \mathrm{~nm}$ ) and diminishes with large $\mathrm{BC}$ radii. More impor- tantly, we see that $k_{\mathrm{bc} \text {,int }}$ depends very little on either volume fraction or ice effective radius for $V$ less than $\sim 10^{-5}$. Volume fractions between $10^{-11}$ and $10^{-7}$ are represented with a single curve in Fig. 3 because $k_{\mathrm{bc} \text {,int }}$ differences are indistinguishable in this domain. This is important because all field measurements of bulk BC/snow mass concentrations are smaller than $10^{-5}$ (e.g., Clarke and Noone, 1985; Warren and Clarke, 1990; Doherty et al., 2010; Huang et al., 2011), implying that volume fraction might be justifiably neglected in parameterizations of $k_{\mathrm{bc} \text {,int }}$ for $\mathrm{BC}$ in snow. Individual ice grains may, however, contain much larger $\mathrm{BC}$ volume fractions than the mean snowpack concentration, a point we soon re-visit. $k_{\mathrm{bc} \text {,int }}$ begins to decrease at larger volume fractions (Chýlek et al., 1983). Figure 3 shows that the dependency on $V$ is intertwined with ice grain size, with larger grains facilitating a larger reduction in $k_{\mathrm{bc} \text {,int }}$ with increasing $V$, and one that becomes apparent at smaller $V$. With an ice effective radius $r_{\mathrm{i}}=50 \mu \mathrm{m}, k_{\mathrm{bc}}$,int is virtually indistinguishable for 

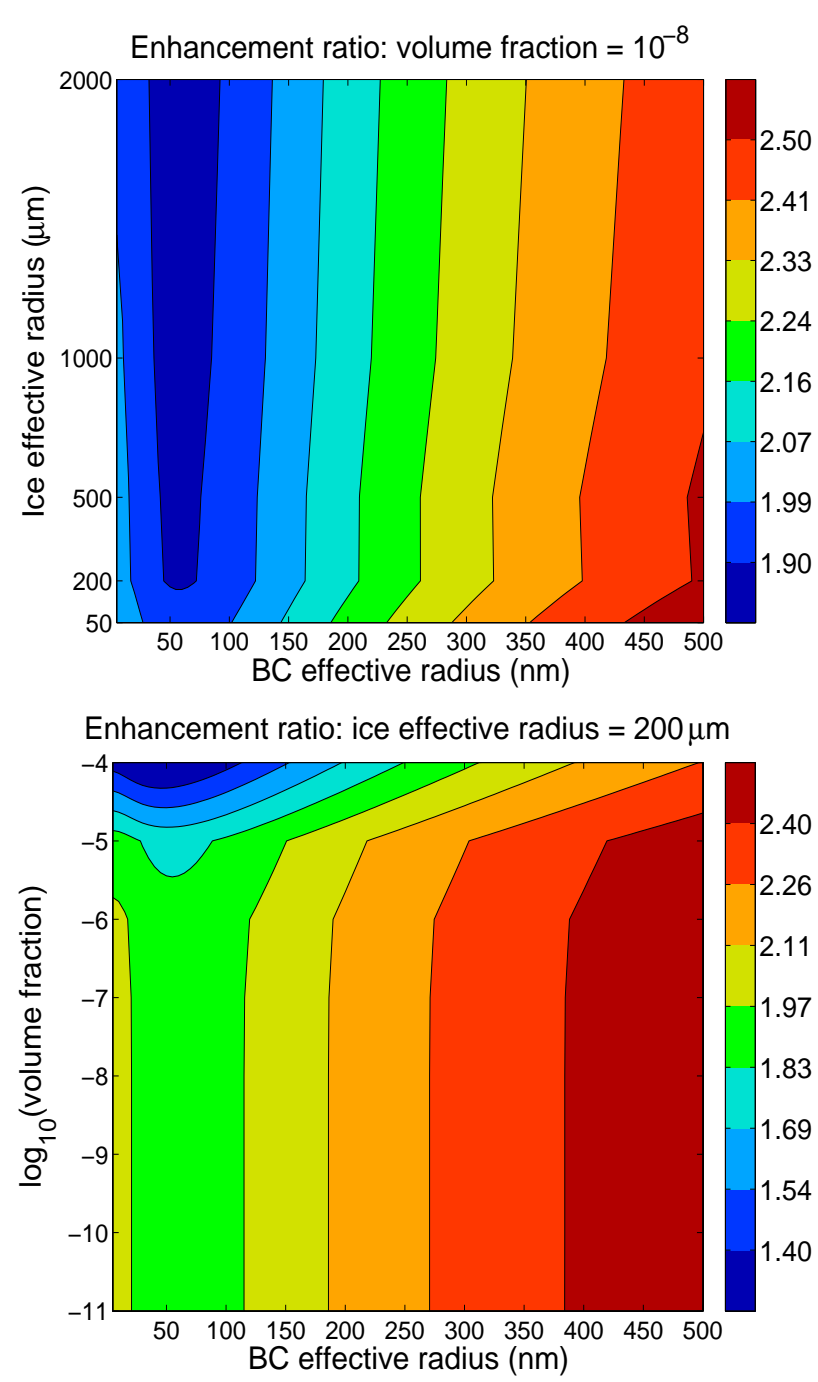

Fig. 4. The $460 \mathrm{~nm}$ enhancement ratio (Eq. 10) of internally-mixed $\mathrm{BC}$ within ice grains, as a function of ice and $\mathrm{BC}$ effective radii, with fixed volume fraction of $10^{-8}$ (top), and as a function of $\mathrm{BC}$ effective radius and volume fraction, with fixed ice effective radius of $200 \mu \mathrm{m}$ (bottom). Data used are the same as those shown in Fig. 3.

all $V<10^{-5}$, whereas with $r_{\mathrm{i}}=2000 \mu \mathrm{m}$ reduction in $k_{\mathrm{bc} \text {,int }}$ is evident at $V=10^{-5}$. Very large volume fractions can actually produce $k_{\mathrm{bc} \text {,int }}<k_{\mathrm{bc} \text {,ext }}(\mathrm{Fig}$. 3c), which is a consequence of the "screening effect" of a large volume of BC particles packed into a single ice grain (Chýlek et al., 1983). This effect also appears in the Bruggeman and Maxwell-Garnett approximations, and is manifested as a sub-linear increase in $k_{\mathrm{bi}}$ with increasing imaginary refractive index, which increases nearly proportionately with increasing $\mathrm{BC}$ volume fraction between $V=10^{-8}$ and $V=10^{-4}$. The relationship between $k_{\mathrm{bi}}$ and the composite refractive index also clearly depends on $\mathrm{BC}$ particle size.

In all cases, as BC particle size approaches zero, $k_{\mathrm{bc} \text {,int }}$ approaches values predicted with the Bruggeman mixing ap-

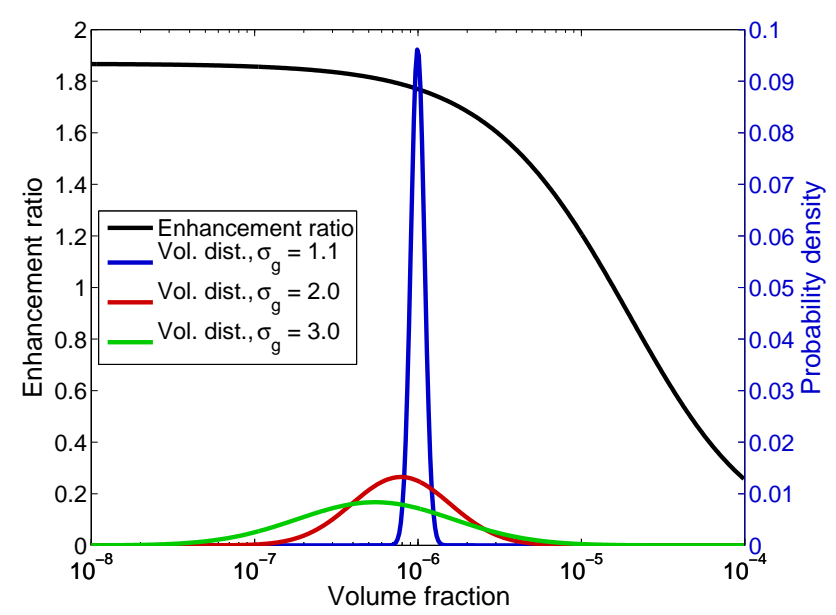

Fig. 5. The enhancement ratio (Eq. 10) calculated with the DEMA as a function of volume fraction (black curve, left axis) for an extreme case with ice effective radius of $2000 \mu \mathrm{m}$ and BC inclusion effective radius of $50 \mathrm{~nm}$. Also shown are three hypothetical distributions of volume fraction (color curves, against the right axis) which all have the same bulk internal volume fraction of $10^{-6}$. At large volume fractions the enhancement ratio drops below 1 because of the screening effect (Chýlek et al., 1983). However, all three distributions of volume fraction yield very similar mean specific absorption cross-sections (Eq. 8).

proximation, as shown with dashed lines in Fig. 3. This is an analytical feature of the DEMA (Chýlek et al., 1984). We also note that by subtracting the pure ice absorption in our definition of $k_{\mathrm{bc} \text {,int }}$ (Eq. 8), we eliminate the "artificial" absorption enhancement at $V<10^{-7}$ that was noted by Chýlek et al. (1983). Because BC (visible) absorption begins to dominate ice absorption at volume fractions greater than $10^{-7}$, Eq. (8) can be accurately approximated in this domain as: $k_{\mathrm{bc}, \text { int }} \approx \sigma_{\mathrm{bi}} / m_{\mathrm{bc}}$.

Figure 4 shows the enhancement ratio (Eq. 10) over different domains of $V$, ice radius, and $\mathrm{BC}$ effective radius, using the same data depicted in Fig. 3. The enhancement ratio is largest with large $\mathrm{BC}$ particle sizes and small volume fractions, exceeding 2 over much of this domain. The enhancement depends very weakly on ice grain size (top panel) and $\mathrm{BC}$ volume fraction when $V<10^{-5}$. At large volume fractions, the screening effect reduces enhancement. Because $k_{\text {bc,ext }}$ is smallest with larger BC sizes (Fig. 3), the large enhancement ratios in this domain are less relevant (i.e., they do not translate into large changes in radiative forcing). For a situation that we might expect to find in remote snowpack, with $\mathrm{BC}$ effective radius of $100 \mathrm{~nm}$, ice effective grain size of $200 \mu \mathrm{m}$, and bulk BC volume fraction of $10^{-8}$, the enhancement ratio would be 1.94 . For this situation, the Bruggeman approximation, representing infinitesimally small inclusions, provides an enhancement ratio of 2.2. However, the Bruggeman enhancement ratio is somewhat ill-defined because $k_{\mathrm{bc} \text {,ext }}$ depends on BC particle size whereas $k_{\mathrm{bc} \text {,int }}$ does 
not. For the volume fraction and ice grain size cited above, the coated-sphere model produces smaller $k_{\mathrm{bc} \text {,int }}$ because it requires a very large BC particle (although the DEMA generally produces larger enhancement ratios than the coatedsphere model for solitary BC inclusions larger than $100 \mathrm{~nm}$ ). Over most of the parameter space relevant to global BC/snow forcing the DEMA enhancement ratio falls into a relatively narrow range of 1.8-2.1. Similarly, Liou et al. (2011) calculated a 1.9-fold increase in co-single-scatter albedo for solitary BC inclusions residing in large ice particles. Encouragingly, this enhancement was nearly identical for BC inclusions in spheres, hexagonal plates, and rough-surface plates (their Fig. 7), suggesting that the absorption enhancement caused by randomly located BC inclusions may be relatively insensitive to the ice shape. Very small BC particles, however, caused slightly greater absorption enhancement in spheres than plates. In snowpack, external BC particles are in contact with ice grains, rather than in a purely suspended interstitial state. Optical studies of BC particles attached to the outside of sulfate aerosols ("quasi-external mixtures") show virtually no absorption enhancement (Liou et al., 2011), or small enhancements of 0-38\% (Fuller et al., 1999) depending on inclusion and host sizes and refractive indices.

\subsection{Variation in inclusion number concentration}

The previous discussion assumes that the internally-mixed $\mathrm{BC}$ is distributed evenly with ice mass (i.e., the inclusion volume fraction is assumed to be identical in all ice grains). Figures 3 and 4, however, show a smaller enhancement at larger volume fractions. Here, we briefly consider the consequences of uneven distributions of internal BC volume. Given a bulk volume fraction $(V)$ of internally-mixed BC (a quantity which might, in theory, be measured), we distribute the internal BC according to lognormal distributions of volume fraction within the ice grains while conserving $V$. We first consider an extreme example: an ice radius of $2000 \mu \mathrm{m}$, an inclusion (BC) effective radius of $50 \mathrm{~nm}$, and a bulk BC volume concentration of $1 \times 10^{-6}$, which would correspond to a mass mixing ratio somewhat larger than $1000 \mathrm{ng} \mathrm{g}^{-1}$, or larger than that measured nearly anywhere on Earth. Figure $3 \mathrm{c}$ suggests that this scenario might yield absorption that is sensitive to the assumed volume fraction distribution. Figure 5 shows, for this scenario, the enhancement ratio as a function of volume fraction (left axis), and three different lognormal distributions of volume fraction which all have the same bulk volume fraction of $1 \times 10^{-6}$. A distribution with $\sigma_{\mathrm{g}}=3.0$ is extremely broad and encroaches somewhat into the $V$ domain of diminishing enhancement, but it also peaks at smaller volume fraction than the more narrow distributions. Therefore, the spread in mean enhancement ratio for the three distributions depicted in Fig. 5 is only 0.004 . Of course one can imagine other distributions of internal BC volume, e.g., bimodal distributions with a few ice grains containing very large amounts of $\mathrm{BC}$ and others containing no
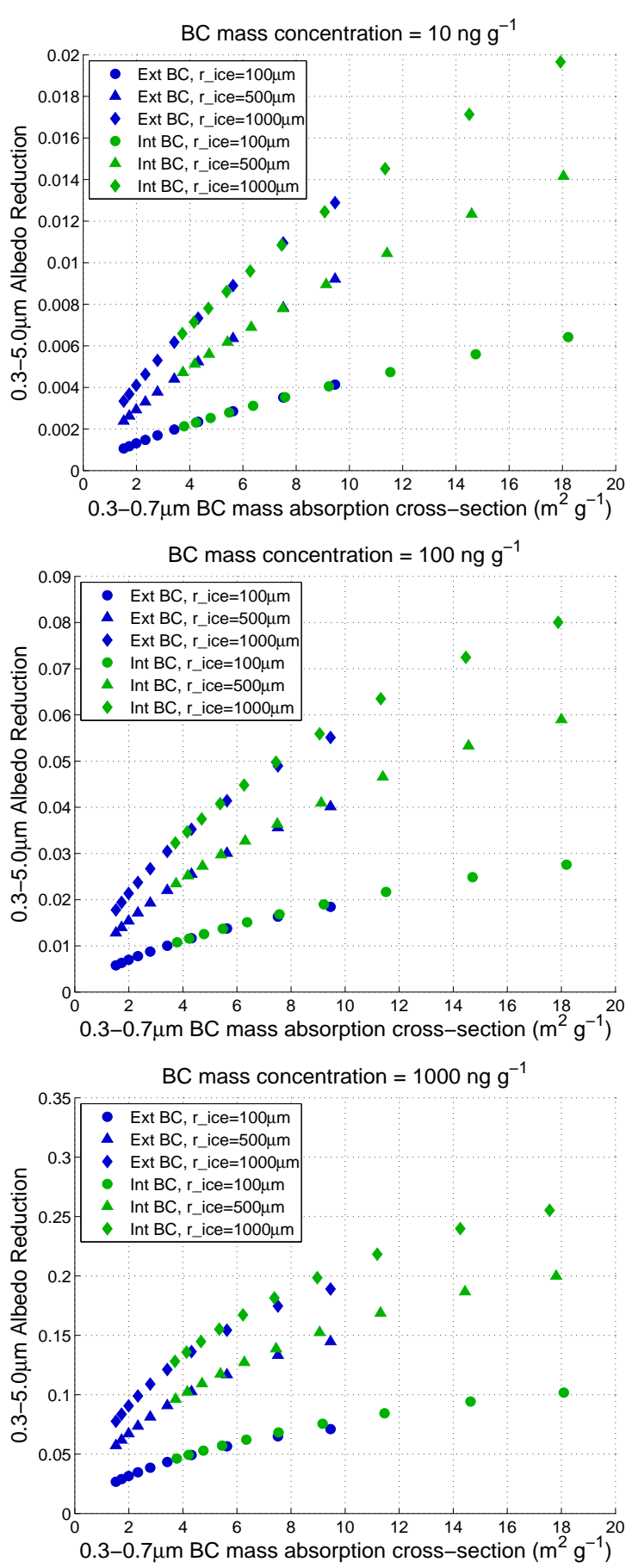

Fig. 6. The broadband $(0.3-5.0 \mu \mathrm{m})$ snow albedo reduction as a function of visible-band $(0.3-0.7 \mu \mathrm{m}) \mathrm{BC}$ mass absorption crosssection for external (blue) and internal BC within ice grains (green). Results are shown for different ice effective radii (symbols) and BC mass concentrations (panels). The internal BC mass absorption cross-section is calculated with Eq. (8). Radiative transfer calculations for internal $\mathrm{BC}$ assume composite $\mathrm{BC} /$ ice species with optical properties calculated with the DEMA. 
or little BC. Such a distribution might be found where snow contains a mixture of crystals containing solitary BC inclusions because they were formed in the atmosphere through the Bergeron-Findeisen process (these crystals may resemble diamond dust), and other crystals contain numerous inclusions because they were formed through aggregation and accretion of small ice crystals or through riming. In these cases, the mean enhancement ratio could be much lower. But for lognormal distributions of volume fraction, the relative amount of internally- and externally-mixed BC is much more important in determining $k_{\mathrm{bc}}$ than the distribution of $\mathrm{BC}$ volume fraction within the ice grains, owing to the weak dependence of absorption enhancement on volume fraction at low $V$.

\subsection{Column albedo change}

We now evaluate the influence of $\mathrm{BC} /$ ice mixing state on snow albedo. With greater specific absorption $\left(k_{\mathrm{bc}}\right)$, we obviously expect $\mathrm{BC}$ within ice to cause a greater reduction in snow albedo, but we also seek to identify whether internal and external $\mathrm{BC}$ mixtures of equal specific absorption have similar influence on snow albedo. One way to visualize this is to examine albedo reduction as a function of $k_{\mathrm{bc}}$ for different mixing states (Fig. 6). To explore this, we apply the SNICAR two-stream model (Flanner et al., 2007, 2009) to calculate snow albedo in 470 spectral bands from $0.3-5.0 \mu \mathrm{m}$. In previous studies we treated the snowpack as an externally-mixed collection of ice grains, BC, and sulfate-coated BC, with the bulk single-scatter albedo weighted by each constituent's extinction optical depth, and the bulk asymmetry parameter weighted by each constituent's extinction optical depth and single-scatter albedo. Here, we incorporate additional BC/ice composite species into the model, with dielectric properties derived from the DEMA and Mie properties, dependent on ice effective radius, $\mathrm{BC}$ volume fraction, and $\mathrm{BC}$ particle size distribution within the ice grains.

Figure 6 shows the spectrally-integrated $(0.3-5.0 \mu \mathrm{m})$ snow albedo reduction as a function of visible-band (0.3$0.7 \mu \mathrm{m}) k_{\mathrm{bc}}$ for external and internal $\mathrm{BC}$ mixtures with different ice effective radii and $\mathrm{BC}$ mass concentrations. Albedo and $k_{\mathrm{bc}}$ are both weighted by the same spectral distribution of surface downwelling flux, which is typical of a mid-latitude winter clear-sky atmosphere. For internal $\mathrm{BC}, k_{\mathrm{bc}}$ was calculated using Eq. (8) and was varied by altering the size distribution of BC from $50-500 \mathrm{~nm}$, with the smallest particles producing the largest $k_{\mathrm{bc}}$ (Fig. 3).

Several points are worth noting. The albedo reduction (and hence radiative forcing) is nearly linear with increasing $k_{\mathrm{bc}}$ at very low $\mathrm{BC}$ concentrations and low $k_{\mathrm{bc}}$ values, but becomes more logarithmic with $k_{\mathrm{bc}}$ at higher $\mathrm{BC}$ concentrations and higher $k_{\mathrm{bc}}$. This is a consequence of absorption saturation, and is a feature of all radiative forcing agents. Second, as noted previously (Warren and Wiscombe, 1980; Flanner et al., 2007), the albedo reduction caused by a given mass of $\mathrm{BC}$ increases with increasing grain size. Third, the albedo reduction is very similar for a given $k_{\mathrm{bc}}$, ice effective radius and $\mathrm{BC}$ mass concentration, regardless of the $\mathrm{BC} /$ ice mixing state. There is some deviation at high $k_{\mathrm{bc}}$ and high $\mathrm{BC}$ concentrations (Fig. 6c), where internal BC/ice composites absorb slightly more solar energy than external mixtures with equal $k_{\mathrm{bc}}$. This is partially a consequence of the arbitrary use of $0.3-0.7 \mu \mathrm{m}$ average $k_{\mathrm{bc}}$ as the independent variable. The bulk absorption efficiency of BC in snow is spectrallydependent, with maximum efficiency occurring where ice $a b-$ sorbs most weakly in the blue and UV-A portions of the spectrum, and thus spectral variations in optical properties could produce equal $0.3-0.7 \mu \mathrm{m} k_{\mathrm{bc}}$ but unequal absorption. A second cause of the larger albedo reduction with internal $\mathrm{BC}$ is that ice crystals containing $\mathrm{BC}$ scatter radiation slightly more strongly in the forward direction than external mixtures of ice and $\mathrm{BC}$, which enables $\mathrm{BC}$ at greater snowpack depth to contribute to absorption and albedo reduction. The $500 \mathrm{~nm}$ bulk asymmetry parameters for a situation with $r_{e}=1000 \mu \mathrm{m}$ and $\mathrm{BC}$ mass concentration of $1000 \mathrm{ng} \mathrm{g}^{-1}$ are 0.890 and 0.893 for, respectively, externally and internally-mixed BC. The asymmetry parameters for randomly-oriented hexagonal columns (Macke et al., 1996) and densely-packed composites (Mishchenko and Macke, 1997) also increase (more substantially) with soot inclusions, although the influence of inclusions on bulk asymmetry parameter appears generally small compared with that of the crystal habit (e.g., Liou et al., 2011).

With some exceptions, the albedo reduction is relatively insensitive to mixing state for equal values of visible-band $k_{\mathrm{bc} \text {,ext }}$ and $k_{\mathrm{bc} \text {,int }}$. This opens the door for a simplified treatment of internal BC/ice mixing within climate models. Full treatment of internal mixing with ice would require the addition of a large number of $\mathrm{BC} /$ ice composite species, causing an impractical increase in computational expense. Our approach is therefore to apply enhancement ratios (Eq. 10) to visible-band $k_{\mathrm{bc}}$ for the internal $\mathrm{BC}$ mass. Thus, the online radiation model represents snow as an externally-mixed collection of ice grains, interstitial BC and (one species of) internal BC. The value of $k_{\mathrm{bc}}$ applied to the internal $\mathrm{BC}$ depends on the $\mathrm{BC}$ and ice effective radii, and is retrieved from a lookup table created from offline DEMA and Mie calculations. Given the insensitivity of $k_{\mathrm{bc}}$,int to $\mathrm{BC}$ volume fraction (Fig. 4), we chose to exclude $V$ as a dimension in the lookup table and fix it at $10^{-8}$. The dependence of $k_{\mathrm{bc}, \text { int }}$ on ice effective radius is also weak, but it is important to remember that albedo reduction from $\mathrm{BC}$ depends strongly on ice grain size, a consequence of multiple scattering and the depth profile of light penetration. In the studies described next, BC effective radius is held constant, whereas ice effective radius evolves based on the local snow state (Flanner and Zender, 2006; Oleson et al., 2010). 


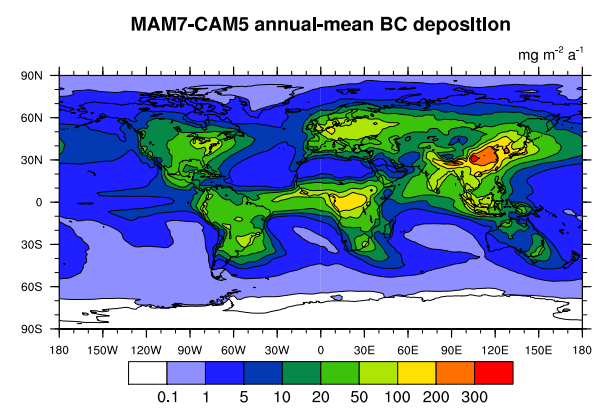

MAM7-CAM5 internal deposition fraction over snow

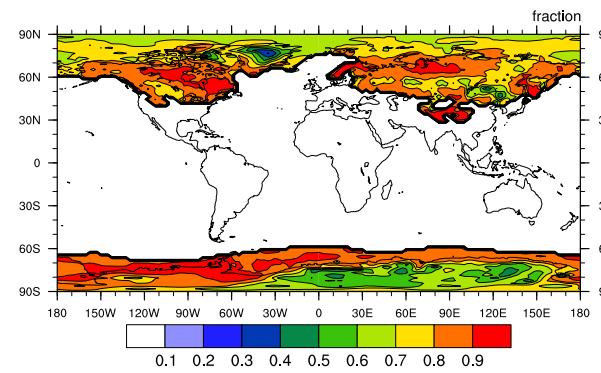

IMPACT-AM3 annual-mean BC deposition

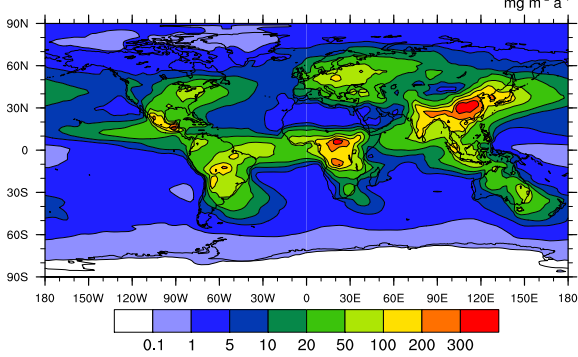

IMPACT-AM3 internal deposition fraction over snow

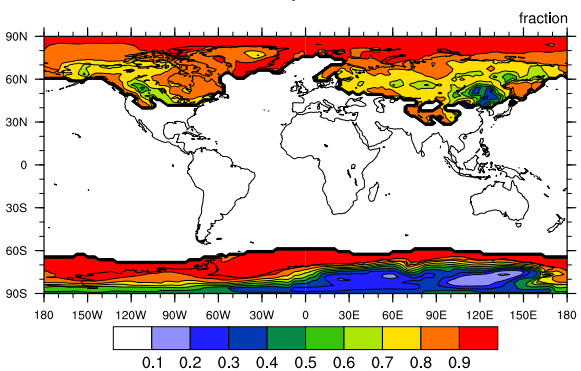

IMPACT-CAM5 annual-mean BC deposition

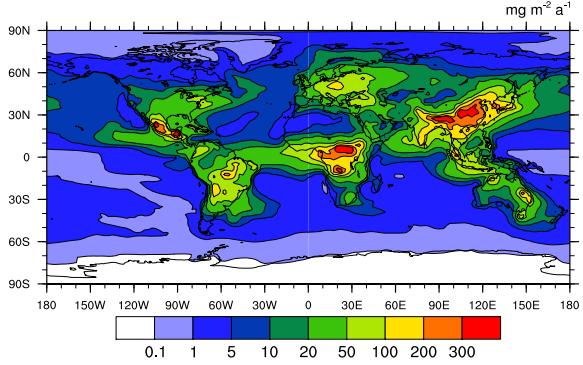

IMPACT-CAM5 internal deposition fraction over snow

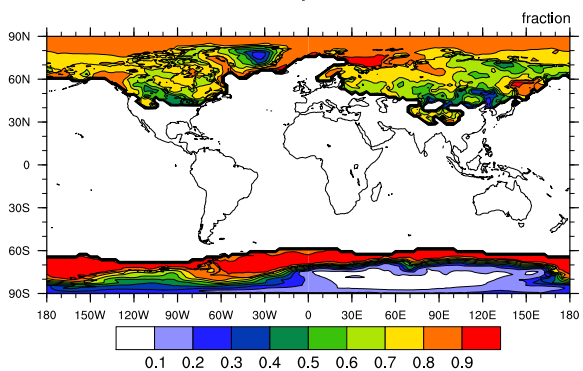

Fig. 7. Annual-mean BC deposition in MAM7-CAM5, IMPACT-AM3, and IMPACT-CAM5 (top, left to right), and the fraction of this deposition occurring within precipitating hydrometeors, averaged temporally over areas with more than $50 \%$ coverage of snow or sea-ice (bottom).
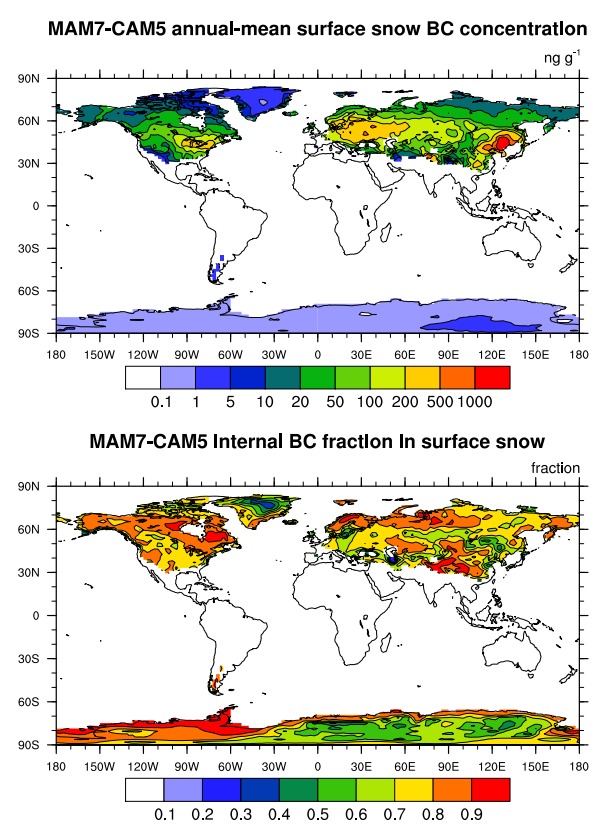

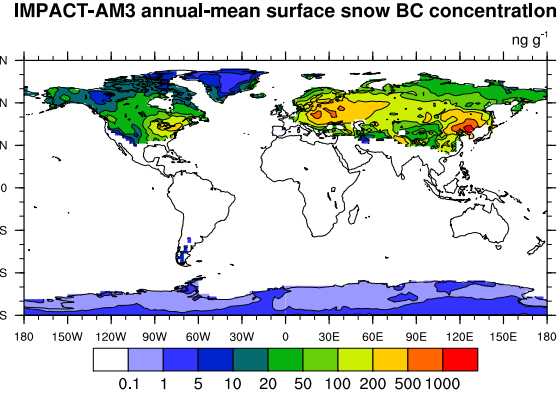

IMPACT-AM3 internal BC fraction in surface snow

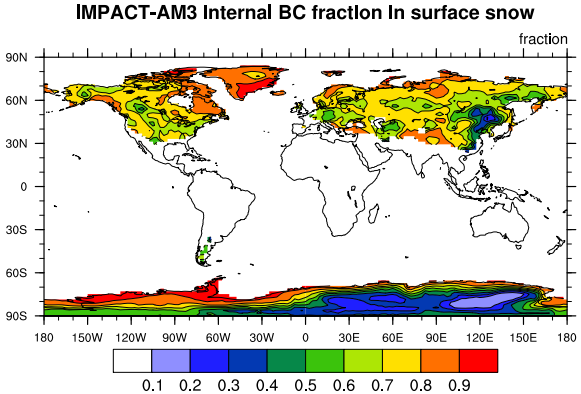

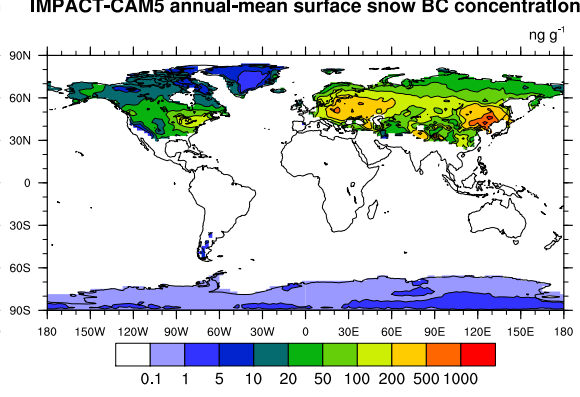

IMPACT-CAM5 internal BC fraction in surface snow

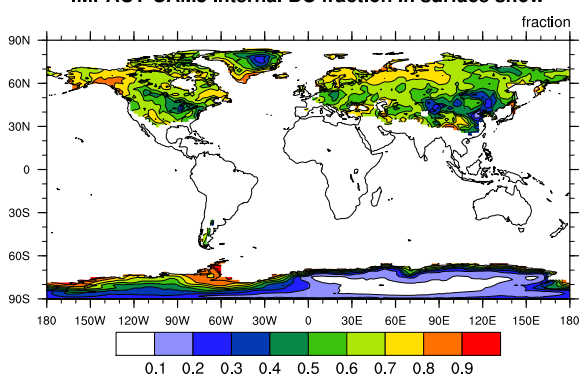

Fig. 8. Annual-mean BC concentration in land-based surface snow simulated with CLM and "Rslow" melt scavenging parameters using MAM7-CAM5, IMPACT-AM3, and IMPACT-CAM5 deposition fields (top, left to right), and the fraction of this BC mass residing within ice grains (bottom).

\subsection{Global studies}

We now apply three global aerosol simulations (MAM7CAM5, IMPACT-AM3, and IMPACT-CAM5) to quantify the proportion of $\mathrm{BC}$ deposition to snow occurring within hydrometeors, and subsequent influences on radiative forcing. Both MAM7 and IMPACT represent a variety of aerosol and aerosol-cloud interactions, described in Sect. 2 and depicted 
MAM7-CAM5 surface snow BC concentration

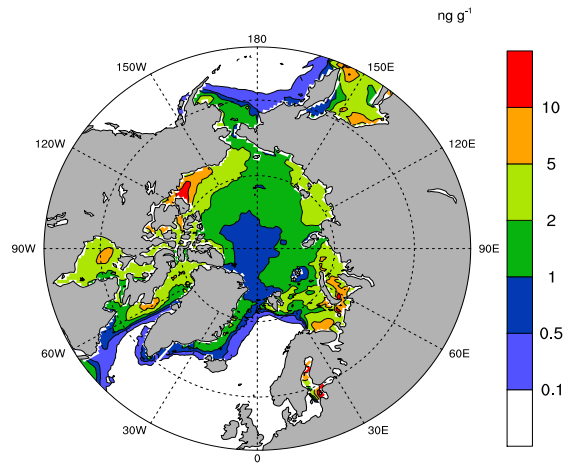

MAM7-CAM5 internal BC fraction in surface snow

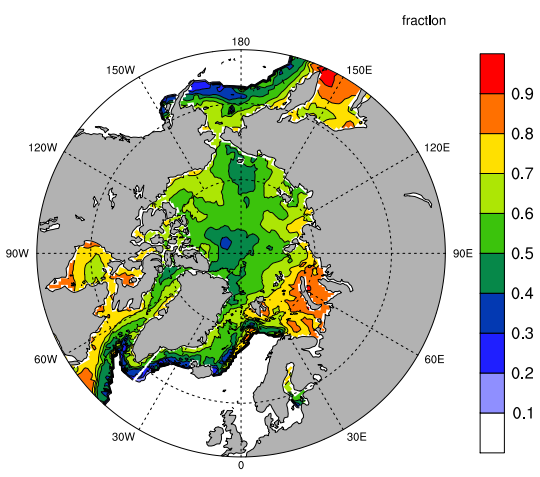

IMPACT-AM3 surface snow BC concentration

ng g-1

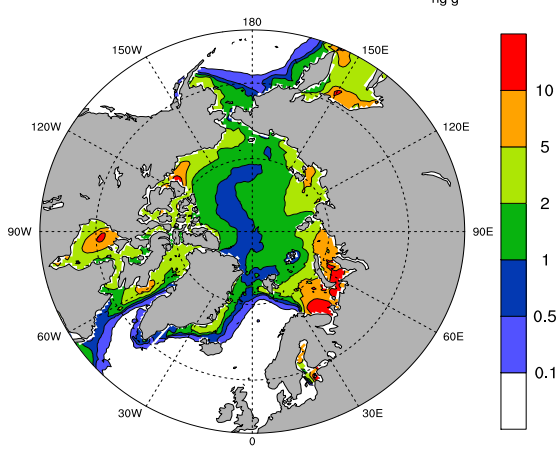

IMPACT-AM3 internal BC fraction in surface snow

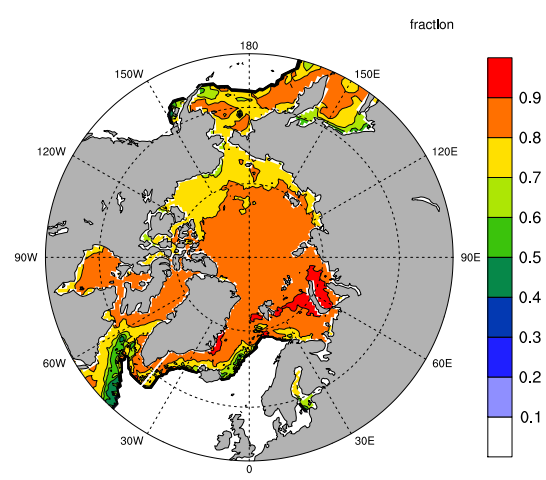

IMPACT-CAM5 surface snow BC concentration

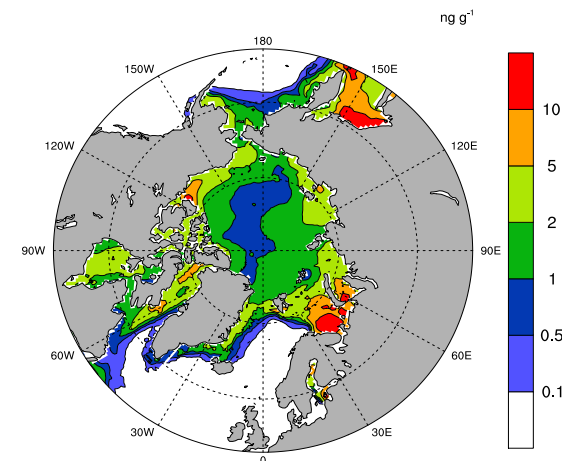

IMPACT-CAM5 internal BC fraction in surface snow

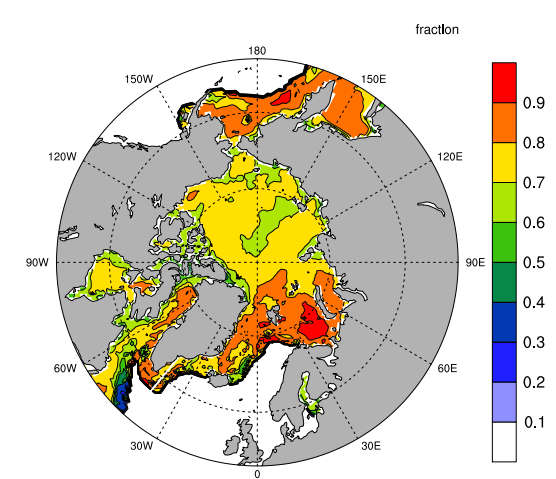

Fig. 9. Annual-mean BC concentration in the surface snow over sea-ice simulated with CICE and "Rslow" melt scavenging parameters using MAM7-CAM5, IMPACT-AM3, and IMPACT-CAM5 deposition fields (top, left to right), and the fraction of this BC mass residing within ice grains (bottom).

in Fig. 1. The primary mechanisms by which $\mathrm{BC}$ enters into hydrometeors depositing to snowpack are through accumulation mode activation, followed by freezing of supercooled droplets through riming or heterogeneous ice nucleation and aggregation/accretion of ice crystals. In MAM7-CAM5, only $2 \%$ of the global atmospheric BC burden resides within cloud hydrometeors, implying that the increase in direct forcing due to cloud-borne BC is very small. Chuang et al. (2002) and Jacobson (2006) reached similar conclusions after applying, respectively, the Maxwell-Garnett approximation and DEMA to cloud-borne BC, but responses of cloud, precipitation, and water vapor to the enhanced absorption can amplify its influence on tropospheric temperatures (Jacobson, $2006,2010)$. Once BC enters into hydrometeors, however, it is much more susceptible to deposition via precipitation processes. Thus, the within-hydrometeor BC deposition fraction is much larger than the cloud-borne burden fraction, carrying important implications for $\mathrm{BC} /$ snow forcing.

Figure 7 shows the annual-mean $\mathrm{BC}$ deposition in all three models and the fraction of deposition over snow and sea-ice that occurs within precipitation hydrometeors (not including $\mathrm{BC}$ attached to the exterior of the hydrometeor, collected by falling precipitation). This fraction is averaged temporally (monthly-resolution) only over gridcells with more than
$50 \%$ snow or sea-ice coverage. All three models show similar patterns of large total deposition near fossil and biomass sources. Both IMPACT models produce more deposition over the Arctic, but also apply higher BC emissions. Global $\mathrm{BC}$ emissions used in MAM7 and IMPACT were 7.7 and $10.5 \mathrm{Tg} \mathrm{yr}^{-1}$, respectively. We note again that the version of MAM7-CAM5 used here includes two parameter changes which slow BC aging and increase the amount of $\mathrm{BC}$ advected to remote regions like the Arctic (Liu et al., 2012). It is also of interest that IMPACT-CAM5 simulates larger Arctic BC burdens but smaller Arctic BC deposition than IMPACT-AM3 (Zhou et al., 2012), demonstrating the importance of meteorology (relative to microphysics) for BC deposition in remote regions. Averaged spatially and temporally over snow and sea-ice, the fractions of BC deposition occurring within hydrometeors in MAM7-CAM5, IMPACT-AM3, and IMPACT-CAM5 are, respectively, $83 \%, 77 \%$, and $71 \%$. Over land-based snow, MAM7 simulates a higher internal deposition fraction than both IMPACT models, but over seaice IMPACT gives a higher fraction. This is caused by a combination of differences in model stratiform precipitation and aerosol processes.

Figures 8 and 9 show the annual-mean BC concentrations and internally-mixed $\mathrm{BC}$ fractions in surface snow 
and sea-ice, as simulated within the CLM and CICE models driven with deposition fields described above. These simulations all apply Rslow (inefficient removal) meltwater scavenging parameters. IMPACT deposition produces larger snowpack BC concentrations over high-latitude Eurasia, Greenland, and the Barents Sea, but overall these models produce remarkably similar high-latitude $\mathrm{BC}$ content. Greater diversity in BC transport to the Arctic was seen in an Aerosol Comparisons between Observations and Models (AEROCOM) study (Koch et al., 2009b). Though different in many regards, the modal aerosol treatment and aerosol-cloud interactions in these two models are similar when taken against the backdrop of all AEROCOM models. The global fractions of internally-mixed BC in surface snow (with Rslow physics) are $72 \%, 72 \%$ and $65 \%$ in MAM7CAM5, IMPACT-AM3, and IMPACT-CAM5. Despite these similarities, IMPACT produces a higher fraction of internal BC over sea-ice whereas MAM7 produces more internal BC in land snow (Figs. 8 and 9). These fractions are smaller than the internal deposition fractions because internal BC is preferentially removed from snowpack with meltwater, owing to its higher scavenging efficiency (Eqs. 11-12). The spatial patterns of internal $\mathrm{BC}$ fraction, however, broadly resemble those of the internal deposition fractions, which are smallest in IMPACT-CAM5. In the sensitivity studies discussed next, internal BC fractions exhibit much greater range (32-73\%) due to different post-depositional transfer mechanisms.

We now look at the enhancement in $\mathrm{BC} /$ snow radiative forcing caused by internal BC/ice mixing. Global annualmean land snow forcing enhancements are listed in Table 1. Control simulations apply external BC optical properties to all $\mathrm{BC}$, whereas experiments apply enhancement ratios to $k_{\mathrm{bc}}$ of internal BC. In the controls (not shown), forcing decreases with increasing BC effective radius because of decreasing $k_{\mathrm{bc}}$ (Fig. 3), with $250 \mathrm{~nm} \mathrm{BC}$ producing about $57 \%$ smaller forcing than $50 \mathrm{~nm} \mathrm{BC}$. The experiments have $34-86 \%$ larger radiative forcing than their respective controls. The enhancement increases with increasing $\mathrm{BC}$ effective radius, as expected from offline calculations (Fig. 4). With a $100 \mathrm{~nm} \mathrm{BC}$ effective radius, The MAM7-CAM5 Rslow, Rfast, Rfast+sub and Rfast+sub+frz experiments produce $66 \%, 63 \%, 56 \%$, and $45 \%$ larger forcings than their respective controls, with decreasing enhancement caused by more efficient removal or transfer of internal BC through meltwater scavenging, sublimation, and freezing of liquid water. The effects of these post-depositional processes on internal BC mass fractions are depicted in Fig. 10, which shows substantial influence over most continental snowpack, but very little influence over Antarctica and central Greenland, where melt rarely occurs and only sublimation reduces the internal BC mass. Freezing (Rfast $+\mathrm{sub}+\mathrm{frz}$ ) and sublimation (Rfast+sub) produce the largest incremental decreases in forcing enhancement. The influence of these processes, however, is intertwined with that of meltwater scavenging. The Rfast+sub and Rfast + sub + frz controls have slightly larger forcings than
Rfast controls because they produce a larger fraction of external $\mathrm{BC}$ in surface snow, subjecting less BC to efficient meltwater scavenging. The IMPACT experiments (especially IMPACT-CAM5) produce smaller enhancements than identical MAM7-CAM5 experiments because of smaller withinhydrometeor deposition fraction over snow surfaces (Fig. 7). Overall these snowpack experiments produce $17-28 \%$ variation in enhancement, depending on the model and BC particle size. Furthermore, larger variation in enhancement with larger BC effective radius is offset by smaller forcing with larger effective radius.

These studies assume different globally uniform BC size distributions to help bracket the uncertainty associated with BC particle size. In MAM7-CAM5, freshly-emitted BC has an effective radius of $95 \mathrm{~nm}$ (number median radius of $40 \mathrm{~nm}$ ) (Liu et al., 2012), which is consistent with biomass sources. In IMPACT, fossil/biofuel and open biomass BC are emitted with effective radii of 96 and $104 \mathrm{~nm}$ (number median radii of 48 and $78 \mathrm{~nm}$ ), respectively, which both result from the superimposition of three measured lognormal modes from different combustion sources (Penner et al., 1998; Liu et al., 2005). Some fossil sources have smaller effective radii on the order of $40 \mathrm{~nm}$ (e.g., Bond et al., 2006a). Aerosol size distributions evolve in both models due to coagulation and condensation of different species. It is reasonable to assume that most soluble mass separates from BC within cloud droplets, so that the size distributions of deposited $\mathrm{BC}$ particles are similar to, or slightly larger than, the emitted size distributions, with coagulation between $\mathrm{BC}$ particles increasing the size distribution of deposited particles in some circumstances. We therefore take $100 \mathrm{~nm}$ as the most consistent effective radius of deposited BC with both atmospheric model representations, and suggest $50 \mathrm{~nm}$ might be more appropriate for some fossil sources. For these two effective radii and three deposition fields, the range of global $\mathrm{BC} /$ snow radiative forcing in cases Rslow and Rfast is 0.019$0.033 \mathrm{~W} \mathrm{~m}^{-2}$. These forcings are smaller than previous estimates (Flanner et al., 2007, 2009), demonstrating the importance of other factors. Reasons why forcing is different in this study are (1) high-latitude BC deposition is smaller here than in previous studies that applied a bulk aerosol model, (2) snow and sea-ice fields (representing 2000-2004) were generated from offline land and sea-ice simulations rather than coupled atmosphere-land-ocean simulations (Flanner et al., 2007, 2009), (3) impurities in snow on sea-ice were treated with a more sophisticated representation (Holland et al., 2012; Briegleb and Light, 2007), and (4) light absorption by dust in snow, which decreases BC forcing, was not considered by Flanner et al. (2007). The focus of this paper, however, is on absorption enhancement caused by internal mixing, rather than on the absolute forcing values, which are determined by many other factors. Recent (e.g., Liu et al., 2012; Huang et al., 2010) and ongoing studies are evaluating the influence of physical parameterizations on simulated BC 
Rslow Internal BC fraction in surface snow

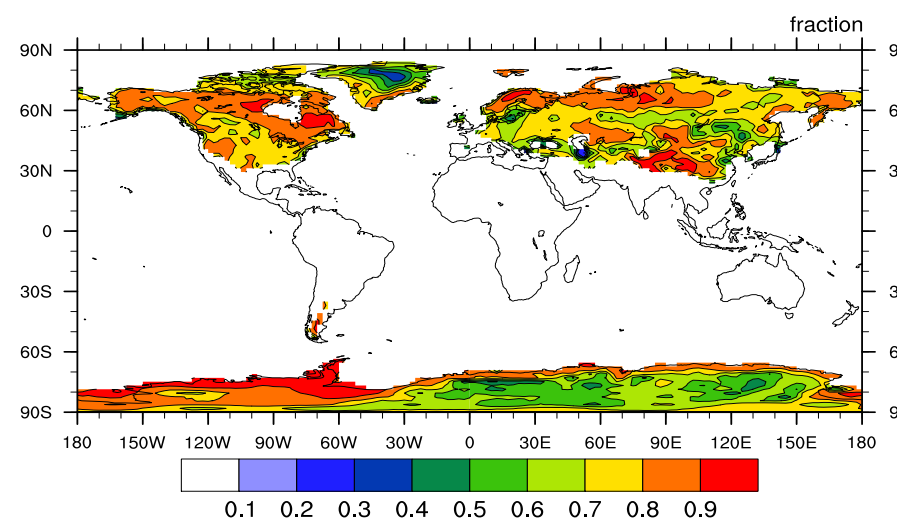

Rfast+sub Internal BC fraction in surface snow

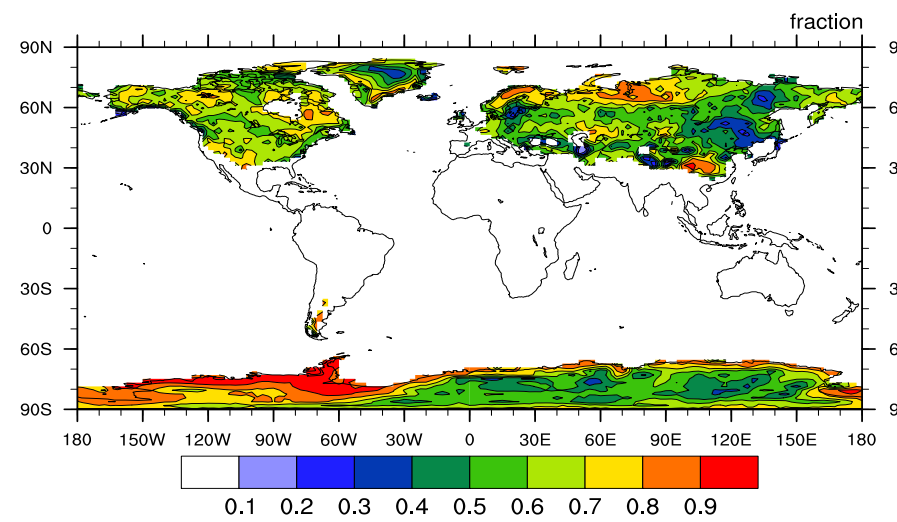

Rfast Internal BC fraction in surface snow

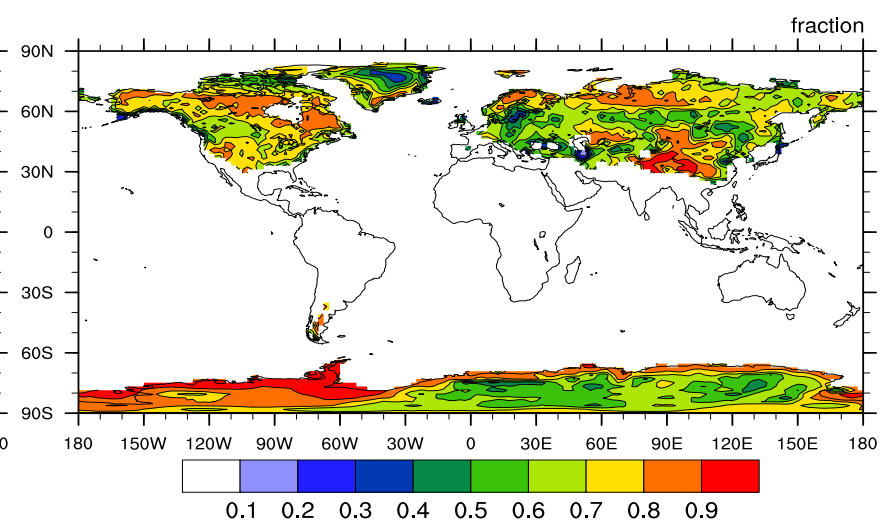

Rfast+sub+frz Internal BC fraction in surface snow

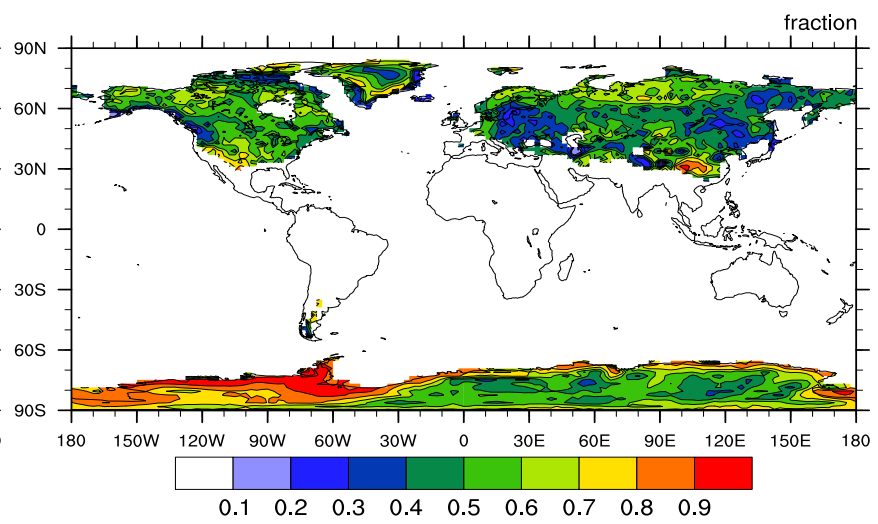

Fig. 10. Annual-mean fraction of surface snow BC mass residing within ice grains, with different representations of snowpack processes. Experiment "Rslow" (top-left) has inefficient removal of internal BC with meltwater, "Rfast" has efficient removal of internal BC, "Rfast+sub" transfers a proportional amount of internal BC to the external state with bulk snow sublimation, and "Rfast + sub + frz" also transfers internal $\mathrm{BC}$ to the external state with freezing of liquid water. BC deposition fields are from simulation MAM7-CAM5.

transport to remote regions, which has an important influence on $\mathrm{BC} /$ snow forcing.

Finally, we emphasize that the forcing enhancement is sensitive to the fraction of $\mathrm{BC}$ deposited to snow and ice within hydrometeors, and there are few direct observations to evaluate this model-derived quantity. Cozic et al. (2007) measured cloud-borne and interstitial BC fractions above the alpine site Jungfraujoch, finding large $(60 \%)$ cloud-borne fractions in liquid clouds, but smaller fractions (5-10\%) in mixed-phase clouds. Moreover, the cloud-borne fraction decreased with increasing ice mass fraction of the cloud. These observations suggest most of the $\mathrm{BC}$ was hydrophilic, but also that the Bergeron-Findeisen process was active in clouds with higher ice fraction. This process likely leads to surface deposition of ice crystals containing few internal BC particles because crystal growth occurs through vapor transfer. Hegg et al. (2011) measured very high BC washout ratios over Svalbard during spring, and applied multiple lines of evidence to attribute these observations to riming in the accretion zone of mixed-phase clouds, which are prevalent in the
Arctic (e.g., Curry et al., 2000). Where it occurs, riming is argued to be the most efficient scavenging mechanism for $\mathrm{BC}$ deposition, and likely entrains many BC particles within individual ice hydrometeors. Measurements at Abisko Sweden, however, show smaller washout ratios, consistent with observations of fewer rimed ice crystals at the surface (Noone and Clarke, 1988). Analysis of decade-long measurements of carbon monoxide $(\mathrm{CO})$ and aerosol absorption coefficients at Barrow and Alert indicates that removal of BC (presumably by wet scavenging) is strongest at warm temperatures and high relative humidities (Garrett et al., 2011). Together, these observations support a conceptual model of efficient BC scavenging in warmer mixed-phase clouds through riming, coalescence and accretion, whereas colder clouds with higher ice fractions experience more rigorous Bergeron-Findeisen growth of ice hydrometeors and consequently less BC scavenging. This picture is also supported by studies showing improved simulation of spring Arctic haze in models with lower cloud-borne BC fractions in ice clouds (Koch et al., 2009b; Liu et al., 2011), in accordance with observations 
(Cozic et al., 2007). Consistent with this, our simulations produce less efficient in-cloud scavenging of $\mathrm{BC}$ in cold regions, evidenced by lower within-hydrometeor $\mathrm{BC}$ deposition fractions over central Antarctica and Greenland (Fig. 7). Measurements also show large spatial and temporal variability in deposition processes. Aircraft measurements over the Arctic during April 2008 showed depleted BC concentrations in the boundary layer over sea-ice (Brock et al., 2011), which together with $\mathrm{CO}$ and ozone measurements indicated dry deposition of surface BC, perhaps caused by increased turbulence near sea-ice leads (Spackman et al., 2010). These aircraft measurements also indicate very little precipitation scavenging of biomass burning plumes aloft (Brock et al., 2011). Prevailing understanding is that below-cloud scavenging of BC by snow is typically quite small (Flossmann and Wobrock, 2010; Hegg et al., 2011; Jacobson, 2003), a feature also exhibited in our simulations.

\subsection{Snowpack processes}

We briefly return to discussion of snow processes which may alter the post-depositional proportions of internal and external BC. Freezing and sublimation have the largest influence on forcing enhancement of the sensitivity studies discussed above, reducing the global-mean surface-layer mass of internal BC by $15-24 \%$ (Fig. 10) and the forcing enhancement by $5-25 \%$, depending on BC size distribution and model. While exclusion of internal BC from sublimating snow grains seems certain, exclusion of $\mathrm{BC}$ from freezing water is much less certain. Thus, we consider the $7-16 \%$ reduction in forcing enhancement from freezing (Table 1) to be an upper bound on this influence. Although the difference in removal efficiencies of internal and external BC is unknown, comparison of the Rslow and Rfast sensitivity studies indicates that this uncertainty may not translate into large uncertainty in forcing enhancement. Meltwater scavenging of internal $\mathrm{BC}$ was 7-fold and 33-fold more efficient than of external $\mathrm{BC}$ in experiments Rslow and Rfast, respectively, but enhancement (relative to paired controls) differed by only $3-6 \%$. The global annual-mean surface-layer mass concentration of internal $\mathrm{BC}$ was about $30 \%$ less in Rfast than Rslow simulations, while total $\mathrm{BC} /$ snow forcing was $13-19 \%$ smaller.

In addition to the post-depositional processes considered above, snow grains metamorphosize through vapor transfer, liquid processes, and sintering at grain boundaries. Snow metamorphism itself is poorly understood, and its influence on the distribution of internally- and externally-located impurities even less so. Brandt et al. (2011) and others suggest that metamorphism should move impurities towards grain boundaries, decreasing the proportion of internal impurities with time. This seems plausible. Sublimation of ice grains exposes internal impurities, while vapor deposition occurs preferentially on ice surfaces (which have much lower saturation vapor pressure than $\mathrm{BC}$ ), leaving impurities exposed.
The sensitivity studies discussed above only consider bulk sublimation from the snowpack and thus underestimate the influence of metamorphic processes. To explore the influence of diffusive vapor flux on BC mixing state with snow, we apply the dry snow aging model developed by Flanner and Zender (2006). This model simulates vapor flux among an ensemble of ice particles, accounting for the temperaturedependent Kelvin Effect, bulk temperature gradient, and snow density. Mass fluxes to and from individual particles are calculated based on ambient pore vapor pressure, which depends on the volume-weighted saturation vapor pressure of the ensemble, the particle-pore spacing, and temperature gradient. Larger grains grow at the expense of smaller ones, causing the snow specific surface area to decrease with time. We assume that gross (metamorphic) sublimation exposes a proportional amount of internal impurity mass, while vapor deposition occurs only on ice and therefore does not alter the internal impurity mass. With this model, we calculate first-order gross sublimation rates ranging from $10^{-13}$ to $10^{-4} \mathrm{~d}^{-1}$, with the fastest rates occurring with high temperature and temperature gradient, broad initial size distribution, and low snow density. Integrated over a month, however, these rates would have a negligible influence on the $\mathrm{BC}$ mixing state with ice. We can achieve higher sublimation rates in this model by assuming sub-saturated air, but relative humidity at shallow depth should be near $100 \%$ (with respect to ice) in the absence of air movement, and we have already accounted for the influence of bulk snow sublimation (dependent on atmospheric relative humidity) via the sensitivity studies described above. We conclude that diffusive metamorphic processes likely occur too slowly to have a substantial impact on the mixing state of $\mathrm{BC}$ during its lifetime of radiative influence. We do not, however, rule out deficiencies in our grain diffusion model. For example, heavily-rimed ice crystals may contain a disproportionate amount of $\mathrm{BC}$ in small spherules near the grain exterior, implying a faster rate of impurity transfer to the external state than simulated here.

Other metamorphism processes are likely more important than vapor diffusion. For example, convection and wind pumping can both transfer vapor at rates orders-of-magnitude faster than diffusion, exposing internal impurities at much faster rates. Conversely, sintering appears to occur preferentially on grain boundaries where impurities are located (Rosenthal et al., 2007), and hence this process may actually increase the proportion of internallymixed impurities. The impurities observed by Rosenthal et al. (2007), however, were mostly filaments that may have acted as dopants, and did not appear to be BC particles. Developing representations for the influences of wind-pumping, convection, and sintering is beyond the scope of this study, but these processes likely play important roles in metamorphism and determine internal impurity fraction in certain environments. Further motivation for studying these processes comes from Brandt et al. (2011), who generated an artificial snowpack with a known mixing ratio of $\mathrm{BC}$ and found that 
the measured spectral albedo, combined with radiative transfer modeling, was consistent with a mass absorption crosssection of externally-mixed BC. This was somewhat surprising because it was speculated, though not confirmed, that the snow was created with internally-mixed $\mathrm{BC}$ and ice.

\section{Conclusions}

We have used optical calculations, column radiation modeling, and global aerosol/snow/climate modeling to quantify plausible ranges of the increase in solar energy absorption associated with BC inclusions in snow grains. Applying the dynamic effective medium approximation (DEMA) (Stroud and Pan, 1978; Chýlek and Srivastava, 1983) we showed that the $460 \mathrm{~nm}$ effective mass absorption cross-section of $\mathrm{BC}$ increases by a factor of $\sim 1.8-2.1$ for ranges of $\mathrm{BC}$ inclusion size distribution, volume fraction, and snow effective radius expected for natural snow surfaces. BC effective radius introduces the most variability in this enhancement, and is not accounted for with the Maxwell-Garnett and Bruggeman approximations. Various aerosol-cloud interactions can produce multiple internal $\mathrm{BC}$ inclusions in precipitating ice hydrometeors, with riming likely the most efficient mechanism. We apply two state-of-the-art aerosol-climate models to simulate global within-hydrometeor BC deposition fractions of $71-83 \%$, averaged temporally over snow and sea-ice surfaces. The simulated global-mean fraction of $\mathrm{BC}$ residing within ice grains of surface snow is $32-73 \%$, smaller than the global deposition fraction because meltwater scavenging, sublimation, and freezing of liquid water preferentially remove internal $\mathrm{BC}$ or transfer it to the external state. Applying a parameterization of the DEMA suitable for global climate models, we calculate that these internal $\mathrm{BC}$ concentrations increase the global $\mathrm{BC} /$ snow radiative forcing by $34-86 \%$ relative to paired control simulations that apply external optical properties to all $\mathrm{BC}$. We believe that uncertainty in this forward-derived estimate arises more from uncertain representation of aerosol-cloud-precipitation interactions than of optical characteristics of $\mathrm{BC} / \mathrm{ice}$ composites. To our knowledge there are no measurements of the relative mass and number concentrations of $\mathrm{BC}$ particles within and external to snow grains, but simple arguments considering measured $\mathrm{BC}$ mass concentrations and $\mathrm{BC} /$ ice particle sizes demonstrate that the number of $\mathrm{BC}$ particles per ice grain ranges from $0.05-10^{9}$. In addition to the melt, freeze and sublimation processes we considered, snow metamorphism likely decreases the proportion of internal BC with time, but simulations with a dry snow aging model show that curvature-driven vapor diffusion does not significantly alter this fraction during the $\mathrm{BC}$ lifetime of radiative influence in snow. This modeling study demonstrates that black carbon in snowpack absorbs substantially more solar radiation because of its inclusion in ice grains.
Acknowledgements. We thank Steve Ghan, Phil Rasch, Yun Qian, and Minghuai Wang for helpful discussions. Research partially supported by NSF ATM-0852775, ARC-1023387, and ATM-0946739. $\mathrm{X}$. Liu acknowledges the support of the US Department of Energy (DOE) Office of Science (BER) Earth System Modeling Program. The Pacific Northwest National Laboratory is operated for DOE by Battelle Memorial Institute under contract DE-AC06-76RLO 1830.

Edited by: P. Stier

\section{References}

Abdul-Razzak, H. and Ghan, S. J.: A parameterization of aerosol activation 2. Multiple aerosol types, J. Geophys. Res., 105, 68376844, 2000.

Ackerman, T. P. and Toon, O. B.: Absorption of visible radiation in atmosphere containing mixtures of absorbing and nonabsorbing particles, Appl. Optics., 20, 3661-3667, 1981.

Aoki, T., Aoki, T., Fukabori, M., Hachikubo, A., Tachibana, Y., and Nishio, F.: Effects of snow physical parameters on spectral albedo and bidirectional reflectance of snow surface, J. Geophys. Res., 105, 10219-10236, 2000.

Aoki, T., Kuchiki, K., Niwano, M., Kodama, Y., Hosaka, M., and Tanaka, T.: Physically based snow albedo model for calculating broadband albedos and the solar heating profile in snowpack for general circulation models, J. Geophys. Res., 116, D11114, doi:10.1029/2010JD015507, 2011.

Barth, M. C., Rasch, P. J., Kiehl, J. T., Benkovitz, C. M., and Schwartz, S. E.: Sulfur chemistry in the National Center for Atmospheric Research Community Climate Model: Description, evaluation, features, and sensitivity to aqueous chemistry, J. Geophys. Res., 105, 1387-1415, 2000.

Bohren, C.: Applicability of effective-medium theories to problems of scattering and absorption by nonhomogenous atmospheric particles, J. Atmos. Sci., 43, 468-475, 1986.

Bohren, C. F. and Huffman, D. R.: Absorption and Scattering of Light by Small Particles, John Wiley \& Sons, New York, NY, USA, 1983.

Bond, T. C. and Bergstrom, R. W.: Light absorption by carbonaceous particles: An investigative review, Aerosol Sci. Tech., 40, 27-67, doi:10.1080/02786820500421521, 2006.

Bond, T. C., Habib, G., and Bergstrom, R. W.: Limitations in the enhancement of visible light absorption due to mixing state, J. Geophys. Res., 111, D20211, doi:10.1029/2006JD007315, 2006 a.

Bond, T. C., Wehner, B., Plewka, A., Wiedensohler, A., Heintzenberg, J., and Charlson, R. J.: Climate-relevant properties of primary particulate emissions from oil and natural gas combustion, Atmos. Environ., 40, 3574-3587, doi:10.1016/j.atmosenv.2005.12.030, 2006b.

Brandt, R. E., Warren, S. G., and Clarke, A. D.: A controlled snowmaking experiment testing the relation between black carbon content and reduction of snow albedo, 116, D08109, doi:10.1029/2010JD015330, 2011.

Briegleb, B. P. and Light, B.: A Delta-Eddington multiple scattering parameterization for solar radiation in the sea ice component of the Community Climate System Model, Tech. Rep. NCAR/TN472+STR, National Center for Atmospheric Research, 2007. 
Brock, C. A., Cozic, J., Bahreini, R., Froyd, K. D., Middlebrook, A. M., McComiskey, A., Brioude, J., Cooper, O. R., Stohl, A., Aikin, K. C., de Gouw, J. A., Fahey, D. W., Ferrare, R. A., Gao, R.-S., Gore, W., Holloway, J. S., Hübler, G., Jefferson, A., Lack, D. A., Lance, S., Moore, R. H., Murphy, D. M., Nenes, A., Novelli, P. C., Nowak, J. B., Ogren, J. A., Peischl, J., Pierce, R. B., Pilewskie, P., Quinn, P. K., Ryerson, T. B., Schmidt, K. S., Schwarz, J. P., Sodemann, H., Spackman, J. R., Stark, H., Thomson, D. S., Thornberry, T., Veres, P., Watts, L. A., Warneke, C., and Wollny, A. G.: Characteristics, sources, and transport of aerosols measured in spring 2008 during the aerosol, radiation, and cloud processes affecting Arctic Climate (ARCPAC) Project, Atmos. Chem. Phys., 11, 2423-2453, doi:10.5194/acp-11-24232011, 2011.

Chang, H. and Charalampopoulos, T. T.: Determination of the wavelength dependence of refractive indices of flame soot, P. Roy. Soc. Lond. A Mat., 430, 577-591, 1990.

Chen, Y., Kreidenweis, S. M., McInnes, L. M., Rogers, D. C., and DeMott, P. J.: Single particle analyses of ice nucleating aerosols in the upper troposphere and lower stratosphere, Geophys. Res. Lett., 25, 1391-1394, 1998.

Chuang, C. C., Penner, J. E., Prospero, J. M., Grant, K. E., Rau, G. H., and Kawamoto, K.: Cloud susceptibility and the first aerosol indirect forcing: Sensitivity to black carbon and aerosol concentrations, J. Geophys. Res, 107, 4564, doi:10.1029/2000JD000215, 2002.

Chýlek, P. and Srivastava, V.: Dielectric constant of a composite inhomogeneous medium, Phys. Rev. B, 27, 5098-5106, doi:10.1103/PhysRevB.27.5098, 1983.

Chýlek, P., Ramaswamy, V., and Srivastava, V.: Albedo of sootcontaminated snow, J. Geophys. Res., 88, 10837-10843, 1983.

Chýlek, P., Ramaswamy, V., and Cheng, R. J.: Effect of graphitic carbon on the albedo of clouds, J. Atmos. Sci., 41, 3076-3084, doi:10.1175/1520-0469(1984)041<3076:EOGCOT>2.0.CO;2, 1984.

Chýlek, P., Videen, G., Wong, J. G. D., Pinnick, R. G., Ngo, D., and Klett, J. D.: Black carbon and absorption of solar radiation by clouds, J. Geophys. Res., 101, 23365-23371, 1996.

Clarke, A. and Noone, K.: Soot in the Arctic: A cause for perturbation in radiative transfer, J. Geophys. Res., 19, 2045-2053, 1985.

Cozic, J., Verheggen, B., Mertes, S., Connolly, P., Bower, K., Petzold, A., Baltensperger, U., and Weingartner, E.: Scavenging of black carbon in mixed phase clouds at the high alpine site Jungfraujoch, Atmos. Chem. Phys., 7, 1797-1807, doi:10.5194/acp-7-1797-2007, 2007.

Cullen, D. and Baker, I.: Observations of impurities in ice, Microsc. Res. Techniq., 55, 198-207, 2001.

Curry, J. A., Hobbs, P. V., King, M. D., Randall, D. A., Minnise, P., Isaac, G. A., Pinto, J. O., Uttal, T., Bucholtz, A., Cripe, D. G., Gerber, H., Fairall, C. W., Garrett, T. J., Hudson, J., Intrieri, J. M., Jakob, C., Jensen, T., Lawson, P., Marcotte, D., Nguyen, L., Pilewskie, P., Rangno, A., Rogers, D. C., Strawbridge, K. B., Valero, F. P. J., Williams, A. G., and Wyliep, D.: FIRE Arctic clouds experiment, B. Am. Meteorol. Soc., 81, 5-29, 2000.

Danielsen, R. E., Moore, D. R., and van de Hulst, H. C.: The transfer of visible radiation through clouds, J. Atmos. Sci., 26, 10781087, 1969.

DeMott, P. J., Chen, Y., Kreidenweis, S. M., Rogers, D. C., and Sherman, D. E.: Ice formation by black carbon particles, Geo- phys. Res. Lett, 26, 2429-2432, 1999.

DeMott, P. J., Petters, M. D., Prenni, A. J., Carrico, C. M., Kreidenweis, S. M., Collett Jr., J. L., and Moosmüller, H.: Ice nucleation behavior of biomass combustion particles at cirrus temperatures, J. Geophys. Res., 114, D16205, doi:10.1029/2009JD012036, 2009.

Doherty, S. J., Warren, S. G., Grenfell, T. C., Clarke, A. D., and Brandt, R. E.: Light-absorbing impurities in Arctic snow, Atmos. Chem. Phys., 10, 11647-11680, doi:10.5194/acp-1011647-2010, 2010.

Donner, L. J., Wyman, B. L., Hemler, R. S., Horowitz, L. W., Ming, Y., Zhao, M., Golaz, J.-C., Ginoux, P., Lin, S.-J., Schwarzkopf, M. D., Austin, J., Alaka, G., Cooke, W. F., Delworth, T. L., Freidenreich, S. M., Gordon, C. T., Griffies, S. M., Held, I. M., Hurlin, W. J., Klein, S. A., Knutson, T. R., Langenhorst, A. R., Lee, H.-C., Lin, Y., Magi, B. I., Malyshev, S. L., Milly, P. C. D., Naik, V., Nath, M. J., Pincus, R., Ploshay, J. J., Ramaswamy, V., Seman, C. J., Shevliakova, E., Sirutis, J. J., Stern, W. F., Stouffer, R. J., Wilson, R. J., Winton, M., Wittenberg, A. T., and Zeng, F.: The dynamical core, physical parameterizations, and basic simulation characteristics of the atmospheric component AM3 of the GFDL global coupled model CM3, J. Climate, 24, 3484-3519, 2011.

Dymarska, M., Murray, B. J., Sun, L., Eastwood, M. L., Knopf, D. A., and Bertram, A. K.: Deposition ice nucleation on soot at temperatures relevant for the lower troposphere, J. Geophys. Res., 111, D04204, doi:10.1029/2004JD005169, 2006.

Easter, R. C., Ghan, S. J., Zhang, Y., Saylor, R. D., Chapman, E. G., Laulainen, N. S., Abdul-Razzak, H., Leung, L. R., Bian, X., and Zaveri, R. A.: MIRAGE: Model description and evaluation of aerosols and trace gases, J. Geophys. Res, 109, D20210, doi:10.1029/2004JD004571, 2004.

Flanner, M. G. and Zender, C. S.: Linking snowpack microphysics and albedo evolution, J. Geophys. Res., 111, D12208, doi:10.1029/2005JD006834, 2006.

Flanner, M. G., Zender, C. S., Randerson, J. T., and Rasch, P. J.: Present day climate forcing and response from black carbon in snow, J. Geophys. Res., 112, D11202, doi:10.1029/2006JD008003, 2007.

Flanner, M. G., Zender, C. S., Hess, P. G., Mahowald, N. M., Painter, T. H., Ramanathan, V., and Rasch, P. J.: Springtime warming and reduced snow cover from carbonaceous particles, Atmos. Chem. Phys., 9, 2481-2497, doi:10.5194/acp-9-24812009, 2009.

Flossmann, A. I. and Wobrock, W.: A review of our understanding of the aerosol-cloud interaction from the perspective of a bin resolved cloud scale modelling, Atmos. Res., 97, 478-497, 2010.

Fuller, K. A.: Scattering and absorption cross sections of compounded spheres, III, Spheres containing arbitrarily located spherical inhomogeneities, J. Opt. Soc. Am. A, 12, 893-904, 1995.

Fuller, K. A., Malm, W. C., and Kreidenweis, S. M.: Effects of mixing on extinction by carbonaceous particles, J. Geophys. Res., 104, 15941-15954, 1999.

Garrett, T. J., Brattström, S., Sharma, S., Worthy, D. E., and Novelli, P.: The role of scavenging in the seasonal transport of black carbon and sulfate to the Arctic, Geophys. Res. Lett., 38, L16805, doi:10.1029/2011GL048221, 2011. 
Gent, P. R., Danabasoglu, G., Donner, L. J., Holland, M. M., Hunke, E. C., Jayne, S. R., Lawrence, D. M., Neale, R. B., Rasch, P. J., Vertenstein, M., Worley, P. H., Yang, Z. L., and Zhang, M.: The Community Climate System Model version 4, J. Climate, 24, 4973-4991, doi:10.1175/2011JCLI4083.1, 2011.

Ghan, S. J. and Easter, R. C.: Impact of cloud-borne aerosol representation on aerosol direct and indirect effects, Atmos. Chem. Phys., 6, 4163-4174, doi:10.5194/acp-6-4163-2006, 2006.

Ghan, S. J. and Zaveri, R. A.: Parameterization of optical properties for hydrated internally mixed aerosol, J. Geophys. Res., 112, D10201, doi:10.1029/2006JD007927, 2007.

Gorbunov, B., Baklanov, A., Kakutkina, N., Windsor, H. L., and Toumi, R.: Ice nucleation on soot particles, J. Aerosol Sci., 32, 199-215, 2001.

Grenfell, T. C. and Warren, S. G.: Representation of a nonspherical ice particle by a collection of independent spheres for scattering and absorption of radiation, J. Geophys. Res., 104, 3769731709, 1999.

Grenfell, T. C., Neshyba, S. P., and Warren, S. G.: Representation of a nonspherical ice particle by a collection of independent spheres for scattering and absorption of radiation: 3 . Hollow columns and plates, J. Geophys. Res., 110, D17203, doi:10.1029/2005JD005811, 2005.

Hansen, J. and Nazarenko, L.: Soot climate forcing via snow and ice albedos, P. Natl. Acad. Sci., 101, 423-428, 2004.

Hansen, J., Sato, M., Ruedy, R., Nazarenko, L., Lacis, A., Schmidt, G. A., Russell, G., Aleinov, I., Bauer, M., Bauer, S., Bell, N., Cairns, B., Canuto, V., Chandler, M., Cheng, Y., Genio, A. D., Faluvegi, G., Fleming, E., Friend, A., Hall, T., Jackman, C., Kelley, M., Kiang, N., Koch, D., Lean, J., Lerner, J., Lo, K., Menon, S., Miller, R., Minnis, P., Novakov, T., Oinas, V., Perlwitz, J., Perlwitz, J., Rind, D., Romanou, A., Shindell, D., Stone, P., Sun, S., Tausnev, N., Thresher, D., Wielicki, B., Wong, T., Yao, M., and Zhang, S.: Efficacy of climate forcings, J. Geophys. Res., 110, D18104, doi:10.1029/2005JD005776, 2005.

Hegg, D. A., Clarke, A. D., Doherty, S. J., and Ström, J.: Measurements of black carbon aerosol washout ratio on Svalbard, Tellus B, 63, 891-900, doi:10.1111/j.1600-0889.2011.00577.x, 2011.

Holland, M. M., Bailey, D. A., Briegleb, B. P., Light, B., and Hunke, E.: Improved Sea Ice Shortwave Radiation Physics in CCSM4: The Impact of Melt Ponds and Aerosols on Arctic Sea Ice, J. Climate, 25, 1413-1430, 2012.

Houghton, H. G.: Physical Meteorology, MIT Press, Cambridge, MA, 1985.

Huang, L., Gong, S., Jia, C. Q., and Lavoue, D.: Importance of deposition processes in simulating the seasonality of the Arctic black carbon aerosol, J. Geophys. Res., 115, D17207, doi:10.1029/2009JD013478, 2010.

Huang, J., Fu, Q., Zhang, W., Wang, X., Zhang, R., Ye, H., and Warren, S. G.: Dust and black carbon in seasonal snow across Northern China, B. Am. Meteorol. Soc., 92, 175-181, doi:10.1175/2010BAMS3064.1, 2011.

Jacobson, M. Z.: Development of mixed-phase clouds from multiple aerosol size distributions and the effect of the clouds on aerosol removal, J. Geophys. Res., 108, 4245, doi:10.1029/2002JD002691, 2003.

Jacobson, M. Z.: Climate response of fossil fuel and biofuel soot, accounting for soot's feedback to snow and sea ice albedo and emissivity, J. Geophys. Res., 109, D21201,
doi:10.1029/2004JD004945, 2004.

Jacobson, M. Z.: Effects of externally-through-internally-mixed soot inclusions within clouds and precipitation on global climate, J. Phys. Chem. A, 110, 6860-6873, doi:10.1021/jp056391r, 2006.

Jacobson, M. Z.: Short-term effects of controlling fossil-fuel soot, biofuel soot and gases, and methane on climate, Arctic ice, and air pollution health, J. Geophys. Res., 115, D14209, doi:10.1029/2009JD013795, 2010.

Koch, D., Menon, S., Genio, A. D., Ruedy, R., Alienov, I., and Schmidt, G. A.: Distinguishing aerosol impacts on climate over the past century, J. Climate, 22, 2659-2677, 2009a.

Koch, D., Schulz, M., Kinne, S., McNaughton, C., Spackman, J. R., Balkanski, Y., Bauer, S., Berntsen, T., Bond, T. C., Boucher, O., Chin, M., Clarke, A., De Luca, N., Dentener, F., Diehl, T., Dubovik, O., Easter, R., Fahey, D. W., Feichter, J., Fillmore, D., Freitag, S., Ghan, S., Ginoux, P., Gong, S., Horowitz, L., Iversen, T., Kirkevåg, A., Klimont, Z., Kondo, Y., Krol, M., Liu, X., Miller, R., Montanaro, V., Moteki, N., Myhre, G., Penner, J. E., Perlwitz, J., Pitari, G., Reddy, S., Sahu, L., Sakamoto, H., Schuster, G., Schwarz, J. P., Seland, Ø., Stier, P., Takegawa, N., Takemura, T., Textor, C., van Aardenne, J. A., and Zhao, Y.: Evaluation of black carbon estimations in global aerosol models, Atmos. Chem. Phys., 9, 9001-9026, doi:10.5194/acp-9-9001-2009, 2009b.

Kumai, M.: Identification of nuclei and concentrations of chemical species in snow crystals sampled at the South Pole, J. Atmos. Sci., 33, 833-841, 1976.

Liou, K. N., Takano, Y., and Yang, P.: Light absorption and scattering by aggregates: Application to black carbon and snow grains, J. Quant. Spectrosc. Ra., 112, 1581-1594, doi:10.1016/j.jqsrt.2011.03.007, 2011.

Liu, H., Jacob, D. J., Bey, I., and Yantosca, R. M.: Constraints from ${ }^{210} \mathrm{~Pb}$ and ${ }^{7} \mathrm{Be}$ on wet deposition and transport in a global threedimensional chemical tracer model driven by assimilated meteorological fields, J. Geophys. Res., 106, 12109-12128, 2001.

Liu, J., Fan, S., Horowitz, L. W., and Levy II, H.: Evaluation of factors controlling long-range transport of black carbon to the Arctic, J. Geophys. Res., 116, D04307, doi:10.1029/2010JD015145, 2011.

Liu, X. and Penner, J. E.: Ice nucleation parameterization for global models, Meteorol. Z., 14, 499-514, doi:10.1127/09412948/2005/0059, 2005.

Liu, X., Penner, J. E., and Herzog, M.: Global modeling of aerosol dynamics: Model description, evaluation, and interactions between sulfate and nonsulfate aerosols, J. Geophys. Res., 110, D18206, doi:10.1029/2004JD005674, 2005.

Liu, X., Penner, J. E., Ghan, S. J., and Wang, M.: Inclusion of ice microphysics in the NCAR Community Atmospheric Model Version 3 (CAM3), J. Climate, 20, 4526-4547, doi:10.1175/JCLI4264.1, 2007.

Liu, X., Easter, R. C., Ghan, S. J., Zaveri, R., Rasch, P., Shi, X., Lamarque, J.-F., Gettelman, A., Morrison, H., Vitt, F., Conley, A., Park, S., Neale, R., Hannay, C., Ekman, A. M. L., Hess, P., Mahowald, N., Collins, W., Iacono, M. J., Bretherton, C. S., Flanner, M. G., and Mitchell, D.: Toward a minimal representation of aerosols in climate models: description and evaluation in the Community Atmosphere Model CAM5, Geosci. Model Dev., 5, 709-739, doi:10.5194/gmd-5-709-2012, 2012. 
Macke, A., Mishchenko, M., and Cairns, B.: The influence of inclusions on light scattering by large ice particles, J. Geophys. Res., 101, 23311-23316, 1996.

Magono, C., Endoh, T., Ueno, F., Kubota, S., and Itasaka, M.: Direct observations of aerosols attached to falling snow crystals, Tellus, 31, 102-114, 1979.

Mari, C., Jacob, D. J., and Bechtold, P.: Transport and scavenging of soluble gases in a deep convective cloud, J. Geophys. Res., 105, 22255-22268, 2001.

Maxwell Garnett, J. C.: Colours in metal glasses and in metallic films, Philos. Tr. R. Soc. S.-A, 203, 385-420, doi:10.1098/rsta.1904.0024, 1904.

Meyers, M. P., DeMott, P. J., and Cotton, W. R.: New primary-ice nucleation parameterizations in an explicit cloud model, J. Appl. Meteorol., 31, 708-721, 1992.

Mishchenko, M. I. and Macke, A.: Asymmetry parameters of the phase function for isolated and densely packed spherical particles with multiple internal inclusions in the geometric optics limit, J. Quant. Spectrosc. Ra., 57, 767-794, doi:10.1016/S00224073(97)00012-5, 1997.

Mishchenko, M. I., Hovenier, J. W., and Travis, L. D. (Eds.): Light scattering by nonspherical particles - Theory, measurements, and applications, Academic Press, 2000.

Möhler, O., Büttner, S., Linke, C., Schnaiter, M., Saathoff, H., Stetzer, O., Wagner, R., Krämer, M., Mangold, A., Ebert, V., and Schurath, U.: Effect of sulfuric acid coating on heterogeneous ice nucleation by soot aerosol particles, J. Geophys. Res, 110, D11210, doi:10.1029/2004JD005169, 2005.

Morrison, H. and Gettelman, A.: A new two-moment bulk stratiform cloud microphysics scheme in the Community Atmospheric Model (CAM3), Part I: Description and numerical tests, J. Climate, 21, 3642-3659, 2008.

Neshyba, S., Grenfell, T., and Warren, S.: Representation of a nonspherical ice particle by a collection of independent spheres for scattering and absorption of radiation: 2. Hexagonal columns and plates, J. Geophys. Res., 108, 4448, doi:10.1029/2002JD003302, 2003.

Niessner, R., Daeumer, B., and Klockow, D.: Investigation of surface properties of ultrafine particles by application of a multistep condensation nucleus counter, Aerosol Sci. Tech., 12, 953-963, 1990.

Noone, K. J. and Clarke, A. D.: Soot scavenging measurements in Arctic snowfall, Atmos. Environ., 22, 2773-2778, 1988.

Oleson, K. W., Lawrence, D. M., Bonan, G. B., Flanner, M. G., Kluzek, E., Lawrence, P. J., Levis, S., Swenson, S. C., Thornton, P. E., Dai, A., Decker, M., Dickinson, R., Feddema, J., Heald, C. L., Hoffman, F., Lamarque, J.-F., Mahowald, N., Niu, G.-Y., Qian, T., Randerson, J., Running, S., Sakaguchi, K., Slater, A., Stöckli, R., Wang, A., Yang, Z.-L., Zeng, X., and Zeng, X.: Technical Description of version 4.0 of the Community Land Model (CLM), Tech. Rep. NCAR/TN-478 + STR, National Center for Atmospheric Research, 2010.

Painter, T. H., Dozier, J., Roberts, D. A., Davis, R. E., and Greene, R. O.: Retrieval of subpixel snow-covered area and grain size from imaging spectrometer data, Remote. Sens. Environ., 85, 6477, 2003.

Painter, T. H., Deems, J. S., Belnap, J., Hamlet, A. F., Landry, C. C., and Udall, B.: Response of Colorado River runoff to dust radiative forcing in snow, P. Natl. Acad. Sci., 107, 17125-17130, doi:10.1073/pnas.0913139107, 2010.

Penner, J. E., Chuang, C. C., and Grant, K.: Climate forcing by carbonaceous and sulfate aerosols, Clim. Dynam., 14, 839-851, 1998.

Rasch, P. J., Barth, M. C., Kiehl, J. T., Schwartz, S. E., and Benkovitz, C. M.: A description of the global sulfur cycle and its controlling processes in the National Center for Atmospheric Research Community Climate Model, J. Geophys. Res., 105, 13671385, 2000.

Rogers, R. R. and Yau, M. K.: A Short Course in Cloud Physics, Pergamon Press, Oxford, UK, 3rd Edn., 1994.

Rosenthal, W., Saleta, J., and Dozier, J.: Scanning electron microscopy of impurity structures in snow, Cold. Reg. Sci. Technol., 47, 80-89, 2007.

Rypdal, K., Rive, N., Berntsen, T. K., Klimont, Z., Mideksa, T. K., Myhre, G., and Skeie, R. B.: Costs and global impacts of black carbon abatement strategies, Tellus B, 61, 625-641, 2009.

Schwarz, J. P., Spackman, J. R., Gao, R., Watts, L. A., Stier, P., Schulz, M., Davis, S. M., Wofsy, S. C., and Fahey, D. W.: Global-scale black carbon profiles observed in the remote atmosphere and compared to models, Geophys. Res. Lett., 37, L18812, doi:10.1029/2010GL044372, 2010.

Seinfeld, J. H. and Pandis, S. N.: Atmospheric Chemistry and Physics, John Wiley \& Sons, New York, NY, USA, 1998.

Skeie, R. B., Berntsen, T., Myhre, G., Pedersen, C. A., Ström, J., Gerland, S., and Ogren, J. A.: Black carbon in the atmosphere and snow, from pre-industrial times until present, Atmos. Chem. Phys., 11, 6809-6836, doi:10.5194/acp-11-6809-2011, 2011.

Spackman, J. R., Gao, R. S., Neff, W. D., Schwarz, J. P., Watts, L. A., Fahey, D. W., Holloway, J. S., Ryerson, T. B., Peischl, J., and Brock, C. A.: Aircraft observations of enhancement and depletion of black carbon mass in the springtime Arctic, Atmos. Chem Phys., 10, 9667-9680, doi:10.5194/acp-10-9667-2010, 2010.

Spaulding, N. E., Meese, D. A., and Baker, I.: Advanced microstructural characterization of four East Antarctic firn/ice cores, J. Glaciol., 57, 796-810, 2011.

Stroud, D. and Pan, F. P.: Self-consistent approach to electromagnetic wave propagation in composite media: Application to model granular metals, Phys. Rev. B, 17, 1602-1610, doi:10.1103/PhysRevB.17.1602, 1978.

Sturm, M. and Benson, C. S.: Vapor transport, grain growth and depth-hoar development in the subarctic snow, J. Glaciol., 43, 42-59, 1997.

Toon, O. B. and Ackerman, T. P.: Algorithms for the calculation of scattering by stratified spheres, Appl. Optics, 20, 3657-3660, 1981.

Videen, G. and Chýlek, P.: Scattering by a composite sphere with an absorbing inclusion and effective medium approximations, Opt. Commun., 158, 1-6, 1998.

Videen, G., Ngo, D., and Chýlek, P.: Effective-medium predictions of absorption by graphitic carbon in water droplets, Opt. Lett., 19, 1675-1677, 1994.

Wang, M. H., Penner, J. E., and Liu, X. H.: Coupled IMPACT aerosol and NCAR CAM3 model: Evaluation of predicted aerosol number and size distribution, J. Geophys. Res., 114, D06302, doi:10.1029/2008jd010459, 2009.

Warren, S.: Optical properties of snow, Rev. Geophys., 20, 67-89, 1982. 
Warren, S. G. and Brandt, R. E.: Optical constants of ice from the ultraviolet to the microwave: A revised compilation, J. Geophys. Res, 113, D14220, doi:10.1029/2007JD009744, 2008.

Warren, S. G. and Clarke, A.: Soot in the atmosphere and snow surface of Antarctica, J. Geophys. Res., 95, 1811-1816, 1990.

Warren, S. G. and Wiscombe, W.: A model for the spectral albedo of snow. II: Snow containing atmospheric aerosols, J. Atmos. Sci., 37, 2734-2745, 1980.

Wiscombe, W. J. and Warren, S. G.: A model for the spectral albedo of snow. I: Pure snow, J. Atmos. Sci., 37, 2712-2733, 1980.
Yasunari, T. J., Koster, R. D., Lau, K. M., Aoki, T., Sud, Y. C., Yamazaki, T., Motoyoshi, H., and Kodama, Y.: Influence of dust and black carbon on the snow albedo in the NASA Goddard Earth Observing System version 5 land surface model, J. Geophys. Res., 116, D02210, doi:10.1029/2010JD014861, 2011.

Zhou, C., Penner, J. E., Ming, Y., and Huang, X.: Differences in predicted off-line aerosol effects from CAM5 and AM3, Atmos. Chem. Phys. Disc., in preparation, 2012. 